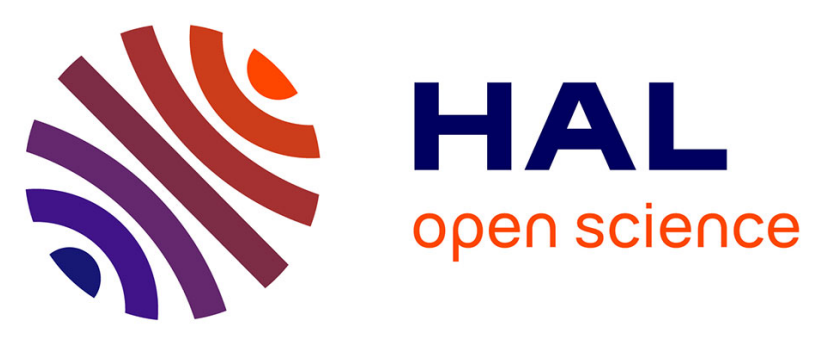

\title{
PbsP, a cell wall-anchored protein that binds plasminogen to promote hematogenous dissemination of Group B Streptococcus.
}

Marco Buscetta, Arnaud Firon, Giampiero Pietrocola, Carmelo Biondo, Giuseppe Mancuso, Angelina Midiri, Letizia Romeo, Roberta Galbo, Mario Venza, Isabella Venza, et al.

\section{To cite this version:}

Marco Buscetta, Arnaud Firon, Giampiero Pietrocola, Carmelo Biondo, Giuseppe Mancuso, et al.. PbsP, a cell wall-anchored protein that binds plasminogen to promote hematogenous dissemination of Group B Streptococcus.. Molecular Microbiology, 2016, 101 (1), pp.27-41. 10.1111/mmi.13357 . pasteur-01308716

\section{HAL Id: pasteur-01308716}

\section{https://hal-pasteur.archives-ouvertes.fr/pasteur-01308716}

Submitted on 7 Mar 2017

HAL is a multi-disciplinary open access archive for the deposit and dissemination of scientific research documents, whether they are published or not. The documents may come from teaching and research institutions in France or abroad, or from public or private research centers.
L'archive ouverte pluridisciplinaire HAL, est destinée au dépôt et à la diffusion de documents scientifiques de niveau recherche, publiés ou non, émanant des établissements d'enseignement et de recherche français ou étrangers, des laboratoires publics ou privés.

$$
\text { Copyright }
$$




\title{
PbsP, a cell wall-anchored protein that binds plasminogen
}

\section{to promote hematogenous dissemination of Group B Streptococcus}

\author{
Marco Buscetta ${ }^{1,2}$, Arnaud Firon ${ }^{2}$, Giampiero Pietrocola $^{3}$,
} Carmelo Biondo ${ }^{1}$, Giuseppe Mancuso ${ }^{1}$, Angelina Midiri ${ }^{1}$, Letizia Romeo ${ }^{1}$,

Roberta Galbo ${ }^{1}$, Mario Venza ${ }^{1}$, Isabella Venza ${ }^{1}$, Pierre-Alexandre Kaminski ${ }^{2}$, Myriam

Gominet $^{2}$, Giuseppe Teti ${ }^{1}$, Pietro Speziale ${ }^{3}$, Patrick Trieu-Cuot ${ }^{2}$ and Concetta Beninati ${ }^{1,4}$

$r$

${ }^{1}$ Metchnikoff Laboratory, Departments of Human Pathology and Medicine, University of Messina, Messina, Italy; ${ }^{2}$ Institut Pasteur, Unité de Biologie des Bactéries Pathogènes à Gram Positif, CNRS ERL3526, 75015 Paris, France; ${ }^{3}$ Department of Molecular Medicine,

Unit of Biochemistry, University of Pavia, Pavia, Italy; ${ }^{4}$ Scylla Biotech Srl, Messina, Italy

Running title: $\mathrm{PbsP}$, a plasminogen-binding protein from $S$. agalactiae

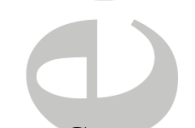

Corresponding author:

Giuseppe Teti

Torre Biologica II p

Policlinico Universitario

Via Consolare Valeria, 1,

98125 Messina, Italy

e-mail, gteti@unime.it;

phone, +39 0902213310 ;

FAX +390902213312.

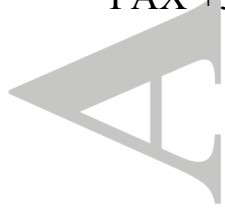

This article has been accepted for publication and undergone full peer review but has not been through the copyediting, typesetting, pagination and proofreading process which may lead to differences between this version and the Version of Record. Please cite this article as an 'Accepted Article', doi: 10.1111/mmi.13357 


\section{Abstract}

Streptococcus agalactiae (Group B Streptococcus or GBS) is a leading cause of invasive infections in neonates whose virulence is dependent on its ability to interact with cells and host components. We here characterized a surface protein with a critical function in GBS pathophysiology. This adhesin, designated PbsP, possesses two Streptococcal Surface Repeat (SSURE) domains, a methionine and lysine-rich region, and a LPXTG cell wall-anchoring motif. PbsP mediates plasminogen (Plg) binding both in vitro and in vivo and we showed that cell surface-bound Plg can be activated into plasmin by tissue plasminogen activator to increase the bacterial extracellular proteolytic activity. Absence of PbsP results in a decreased bacterial transmigration across brain endothelial cells and impaired virulence in a murine model of infection. PbsP is conserved among the main GBS lineages and is a major plasminogen adhesin in non-CC17 GBS strains. Importantly, immunization of mice with recombinant PbsP confers protective immunity. Our results indicate that GBS have evolved different strategies to recruit Plg which indicates that the ability to acquire cell surface proteolytic activity is essential for the invasiveness of this bacterium. 


\section{Introduction}

Adhesion of bacterial pathogens to cells and extracellular macromolecules is an essential process in the long-term relationship between microbes and their hosts (Kline et al., 2009, Nobbs et al., 2009). In particular, many microorganisms are able to bind host plasminogen (Plg) on their surface where its activation is often controlled by host factors (Lahteenmaki et al., 2001, Bergmann \& Hammerschmidt, 2007, Fulde et al., 2013). Plg is an inactive proenzyme (a zymogen) abundant in the plasma that is activated by proteolysis, a reaction usually catalyzed by the host plasminogen activators, tissue-type (tPA) or urokinase-type (uPA), to produce the active serine protease plasmin (Pln). The Plg/Pln fibrinolytic system controls the degradation of fibrin clots and is important for wound repair and extracellular matrix turnover. By coopting the host Plg/Pln system on their surface, bacteria can increase their adhesive properties and proteolytic activities to promote colonization or invasion of host tissues and evasion from the host immune responses (Lahteenmaki et al., 2001, Bergmann \& Hammerschmidt, 2007, Fulde et al., 2013, Foley et al., 2015). Bacteria have evolved independent systems to exploit the host Plg/Pln system at their advantages. Direct binding of host $\mathrm{Plg} / \mathrm{Pln}$ is mediated by specific surface adhesins or conserved ubiquitous moonlighting proteins (enolase, GAPDH) whereas indirect binding is usually mediated by fibrinogen receptors enabling the formation of fibrinogen-plasminogen complex. Despite this common overlapping function, these receptors could be specifically expressed at different steps of the colonization or invasion processes and thus can be individually and sequentially essential for pathogenicity at specific stages of disease development.

Group B Streptococcus (S. agalactiae or GBS) is an important cause of invasive infections, including sepsis and meningitis, in neonates and elderly (Le Doare \& Heath, 2013, Edmond et al., 2012, Skoff et al., 2009). This extracellular pathogen relies on specific adhesins for harmless colonization and/or threatening invasion. Many GBS adhesins characterized to date 
are anchored to the cell wall by a sortase A-dependent mechanism (Nobbs et al., 2009, Mazmanian et al., 1999) and interact with specific host cells or macromolecules during colonization or invasion (Six et al., 2015, Buscetta et al., 2014, Jiang \& Wessels, 2014, Wang et al., 2014, Mu et al., 2014, Papasergi et al., 2011, Tazi et al., 2010). During infections, GBS is able to bind host Plg that is activated to Pln by tPA (or uPA) (Magalhaes et al., 2007). Importantly, GBS secrete a protein named Skizzle that increases Plg activation by host factors (Wiles et al., 2010). The resulting surface-bound protease activity promotes disruption of host barriers thereby contributing to bacterial dissemination and invasiveness (Magalhaes et al., 2013, Six et al., 2015). Plg and Pln binding at the GBS surface is mediated by moonlighting proteins, such as $\alpha$-enolase, glyceraldehyde dehydrogenase and phosphoglycerate kinase, which re-associate with the cell surface following bacterial lysis (Magalhaes et al., 2007, Oliveira et al., 2012, Boone \& Tyrrell, 2012). Depending on their phylogenetic lineage, GBS strains also express unrelated fibrinogen receptors (FbsA, FbsB, or $\mathrm{FbsC}$ ) that catalyse indirect Plg binding (Pietrocola et al., 2005, Gutekunst et al., 2004, Buscetta et al., 2014). In addition, GBS strains belonging to the hypervirulent CC17 clonal complex express a specific multifaceted adhesin, the serine rich repeat Srr2 glycoprotein, with a dual Plg and Fbg binding function (Six et al., 2015, Brochet et al., 2006, Da Cunha et al., 2014).

The pneumococcal protein PfbB (also called PavB) contains a variable number of repetitive sequences (Papasergi et al., 2010, Jensch et al., 2010), referred to as Streptococcal Surface Repeats (SSURE), initially described as a fibronectin (Fnt) binding motif (Bumbaca et al., 2004). However, we showed that this surface protein is a dual Fnt and Plg adhesin (Papasergi et al., 2010). Recently, we identified the GBS SSURE domain-containing protein Gbs0428 by a proteomic analysis of secreted and surface proteins (Papasergi et al., 2013). In this study, we demonstrated that Gbs0428 is a cell wall-anchored surface protein that binds Plg and

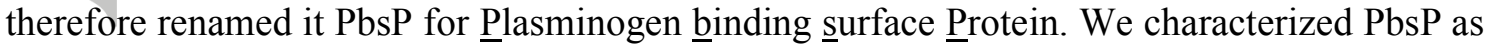


the major Plg binding protein expressed by our reference strain NEM316 (Glaser et al., 2002) and showed that it is expressed by isolates belonging to the main GBS lineages. In addition, we demonstrate that PbsP is necessary for hematogenous GBS dissemination during invasive diseases and that this conserved adhesin induces immune protection.
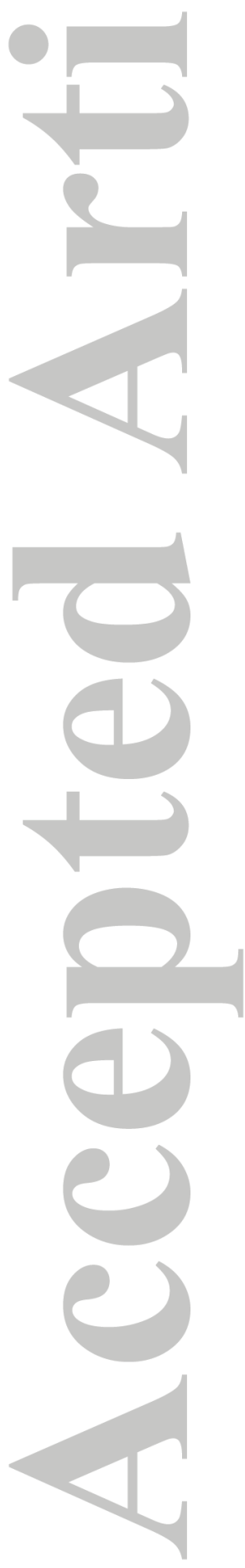


\section{Results}

\section{PbsP is a GBS cell wall-anchored surface protein}

The locus gbs0428 in the genome of GBS NEM316, a capsular serotype III (CPS III) isolate belonging to the clonal complex 23 (CC23), encodes the SSURE domain-containing protein PbsP (Gbs0428) (Glaser et al., 2002). This 521-aa protein contains an NH2-signal peptide bearing a YSIRK sorting motif (Carlsson et al., 2006, Brega et al., 2013), two 150-aa SSURE domains (Bumbaca et al., 2004) displaying 77\% identity, a methionine and lysine-rich (MKrich) region, and a $\mathrm{COOH}$ cell wall-anchoring LPXTG motif (Fig. 1A and B). All sequenced GBS human clinical isolates express a conserved $\mathrm{PbsP}$ protein (99.3\% of identity) containing two SSURE domains (Da Cunha et al., 2014).

The gene encoding PbsP was deleted in-frame in the NEM316 chromosome. The viability, morphology, and growth in Todd-Hewitt broth of the $\triangle p b s P$ mutant were similar to those of the WT parental strain (Fig. S1). Western-blot analysis of GBS cell wall extracts using a polyclonal mouse serum $(\mathrm{pAb})$ against a recombinant $\mathrm{PbsP}$ revealed an hybridizing band present in the WT strain that was absent in the $\Delta p b s P$ and $s r t A^{*}$ mutant derivatives (Fig. 2A).

The $150 \mathrm{kDa}$ band shown in Fig. 2A is apparently the result of a non-specific reaction, since the band was observed in all GBS cell wall extracts examined and also when using an irrelevant antiserum (anti-GST) instead of anti-PbsP serum (data not shown). Taken together, these results confirm that $\mathrm{PbsP}$ is anchored to the cell wall by SrtA (Konto-Ghiorghi et al., 2009, Mazmanian et al., 1999). The apparent molecular weight of this protein is about 40 $\mathrm{kDa}$, a value slightly lower than the predicted $48 \mathrm{kDa}$ of the mature protein. This difference may indicate that $\mathrm{PbsP}$ was further processed upon secretion or during its extraction. As expected from previous transcriptomic and proteomic studies (Lamy et al., 2004, Firon et al.,

2013, Papasergi et al., 2013), expression analysis reveals that $\mathrm{PbsP}$ is overexpressed in the $\triangle \operatorname{cov} R S$ mutant (Fig. 2A). 
Expression of PbsP at the GBS surface was further analyzed by FACS with the same antiPbsP serum. PbsP was detected on the surface of the WT NEM316 strain, but not of the $\triangle p b s P$ or $s r t A^{*}$ mutants, and was highly expressed on the surface of the $\Delta \operatorname{cov} R S$ mutant (Fig. 2B). PbsP expression was also detected, although at different levels, on the surface of other WT GBS strains of different serotypes and clonal complexes (Fig. 2B). The surface display of this protein in GBS NEM316, 6313 (CPS III and CC23 as NEM316), and A909 (CPS Ia, CC1 strain) was similar whereas a lower signal intensity was detected with BM110 and COH1 (both CPS III, CC17) and 2603V/R (CPS V, CC19). Of note, no major difference was observed between the $p b s P$ genes ( $>99.5 \%$ sequence identity) and corresponding promoter regions and translation signal sequences of these strains $(100 \%$ sequence identity) (data not shown). On the other hand, we observed that non-capsulated NEM316 gave a similar signal as the WT strain, suggesting that the polysaccharidic capsule did not significantly mask the display of the protein at the bacterial surface (data not shown).

\section{PbsP is a plasminogen binding protein}

The $\mathrm{PbsP}$ adhesin function(s) were analyzed by ELISA with a purified $\mathrm{rPbsP}$ fusion protein against extracellular matrix or blood components including Plg, Fng, Fnt, collagen, C-reactive protein and the complement components factor-H, factor I, factor-B, C1q and $\mathrm{C} 3$. This analysis revealed that $\mathrm{Plg}$ is the main ligand of $\mathrm{PbsP}$, although low binding levels were observed with other tested components including Fng (Fig. 3A). In the tested conditions, PbsP specifically bound immobilized Plg in a dose-dependent and saturable manner (Fig. 3B). Binding of PbsP to Plg was confirmed by Far Western blotting experiments in which the recombinant protein was used as either bait or prey (Fig 3C). A dissociation constant (Kd) of $617 \pm 34 \mathrm{nM}$ was measured by surface plasmon resonance using immobilized $\mathrm{rPbsP}$ on the sensor chip and different concentrations of soluble Plg (Fig. 3D).

Binding to fibrin, ECM components and several bacterial proteins is mediated by lysine- 
binding motifs in the kringle domains of Plg. To determine whether these lysine binding sites could be involved in interactions with PbsP, increasing concentrations of lysine or lysine analog $\varepsilon$-aminocaproic acid (6-ACA) were included in the ELISA assay. As a negative control, we used L-alanine, which is a non-charged amino acid. PbsP-Plg interactions were inhibited in a dose-dependent manner in the presence of 6-ACA or L-lysine, but not Lalanine, suggesting an involvement of the lysine-binding sites in Plg (Fig. 3E). Lysyl residues are abundant in the SSURE-1, SSURE-2 and MK-rich domains of PbsP, accounting for 11, 14 and $18 \%$ of the total residues of the protein, respectively. To determine which domain is involved in Plg binding, we purified GST-tagged recombinant proteins corresponding to full length PbsP, SSURE domains 1 and 2, SSURE domain 2, and the MK-rich domain. ELISA assays showed that all four proteins bind immobilized Plg in a saturable and dose-dependent manner (Fig. 3F). However, the MK-rich domain displayed higher binding to Plg as compared to the SSURE domains (Fig. 3F), in agreement with its higher lysyl content. These data suggest that the ability of $\mathrm{PbsP}$ to bind $\mathrm{Plg}$ likely reflects a cooperative activity of the SSURE and MK-rich domains.

As opposed to Group A streptococci, GBS does not express a Plg activator and surface bound Plg needs to be activated by host factors (Magalhaes et al., 2007). We therefore tested the ability of Plg bound to PspP to cleave a Pln-specific chromogenic substrate with or without tPA. As expected, the chromogenic substrate S-2251 was cleaved only in the presence of tPA indicating that PspB-bound Plg could be efficiently converted to Pln (Fig. 4A). We next determined if PbsP-bound Pln can degrade its natural substrate Fng following activation by tPA. SDS-PAGE analysis revealed that the alpha and beta chains were almost entirely degraded following 2 and $4 \mathrm{hr}$ of incubation, respectively, while the gamma chain was resistant to cleavage over a $4 \mathrm{hr}$ time period. No detectable degradation of Fng was detected when either Plg or tPA was omitted (Fig. 4B). Collectively these data indicate that PbsP binds 
Plg by engaging lysine binding sites on the zymogen molecule and that PbsP-bound Plg can be activated to Pln in the presence of exogenous activators, such as tPA, to degrade ECM components.

\section{PbsP contributes to Plg binding on GBS cell surface}

Plg is abundantly present in the host, particularly in the blood, where it reaches concentrations in $\mu \mathrm{M}$ range. We first confirmed recent observations (Magalhaes et al., 2013) that soluble Plg binds on the surface of GBS WT, as revealed with anti-Plg antibodies and FITC-conjugated secondary antibodies (Fig. 5A). Under these conditions, Plg binding on the $\Delta p b s P$ mutant surface was reduced (2-fold) compared to the WT strain, an effect that was abrogated by genetic complementation of the mutant strain (Fig 5A). We next assessed the contribution of PbsP-mediated Plg binding to acquisition of a cell surface proteolytic activity using the Plnspecific chromogenic substrate. Pln activity was only detected in the presence of tPA and paralleled the level of Plg binding to the bacterial surface (Fig 5A and B). Specifically, plasmin activity was markedly reduced in the absence of PbsP and restored to WT levels by genetic complementation (Fig. 5B).

\section{$\mathrm{PbsP}$ is required for adherence to and transmigration across brain endothelial cells}

GBS invades brain endothelial cells and causes infection of the central nervous system, a process involving GBS interaction with host extracellular matrix components. We used the brain endothelial cell line hCMEC/D3 as an established model to test GBS adhesion and transmigration (Magalhaes et al., 2013). As compared to the parental NEM316 strain, the $\triangle p b s P$ mutant was significantly impaired in its ability to adhere to these cells whereas the WT levels of adhesion were restored in the complemented strain (Fig. 6A). However, the levels of adhesion of the $\triangle p b s P$ mutant were slightly higher than those observed with a $s r t A^{*}$ mutant, which might suggest that other LPXTG adhesins participate to these processes. The levels of 
invasion of the $\triangle p b s P$ mutant were also decreased, as compared to the parental NEM316 strain (Fig. 6B). However this effect was likely secondary to the impaired ability of the mutant strain to adhere to hCMED/D3 cells, since the relative invasion rate (defined as the ratio between invading and adhering bacteria) was similar in the parental strain and the $\Delta p b s P$ mutant (data not shown).

Plg binding at the surface of GBS was demonstrated to be important for bacterial migration across endothelial barriers after tPA-mediated activation into Pln (Magalhaes et al., 2013). We first confirmed, using a transwell assay, that the ability of NEM316 to migrate through hCMEC/D3 monolayers was greatly enhanced following incubation with Plg and tPA, but was inhibited by the addition of the lysine analogue 6-ACA (Fig. 6C). Remarkably, crossing of the endothelial barrier by the Plg-coated $\Delta p b s P$ mutant in presence of tPA was almost 2fold less efficient compared to the WT strain, whereas the complemented mutant displayed a WT phenotype (Fig. 6C).

\section{Immunoprotective PbsP contributes to hematogenous colonization of target organs}

To investigate the role of $\mathrm{PbsP}$ in the pathogenesis of invasive GBS infection, we intravenously infected CD-1 mice ( $\mathrm{n}=16$ per GBS strain) with $4 \times 10^{8}$ CFUs of the WT and the $\triangle p b s P$ mutant. The mutant strain was less virulent than the WT NEM316 ( $p<0.05$ by log-rank Kaplan-Meyer) as, by nine days post-infection, only $12 \%$ of mice infected with the WT strain survived compared to $50 \%$ of those infected with $\Delta p b s P$ (Fig. 7A).

To outline the role of PbsP in GBS virulence, we measured the bacterial load in the blood, kidneys, and brains at early time points, i.e. $48 \mathrm{~h}$ post-infection. Similar numbers of WT and $\triangle p b s P$ mutant bacteria were found in the blood, indicating that PbsP did not play a critical role in the maintenance of bacteriemia (Fig. 7B). In contrast, the absence of $\mathrm{PbsP}$ was associated with lower bacterial loads ( $\mathrm{p}<0.05$ by Mann-Whitney $U$ test) in the kidneys and brain compared to the WT (Fig. 7C). These data indicate that PbsP plays an important role in 
the pathogenesis of invasive GBS disease by favoring systemic spreading of bacteria from the blood to other organs, in particular the brain.

Being critical for GBS virulence and cell surface exposed, we next investigated if $\mathrm{PbsP}$ constituted a good candidate to induce active immunization. Adult mice $(\mathrm{n}=10$ per experiment) were immunized with $\mathrm{rPbsP}$ or GST (used as a negative control) and challenged intravenously with $2 \times 10^{8} \mathrm{CFU}$ of NEM316 WT 3 weeks after the last immunization. Under these conditions, immunization with $\mathrm{rPbsP}$ resulted in increased survival $(80 \%$ vs $30 \%$ in GST-immunized control animals; $\mathrm{p}<0.05$ by log-rank Kaplan-Meyer; Fig. 8). These data indicate that immunization with $\mathrm{PbsP}$ induces efficient protection against GBS infection.

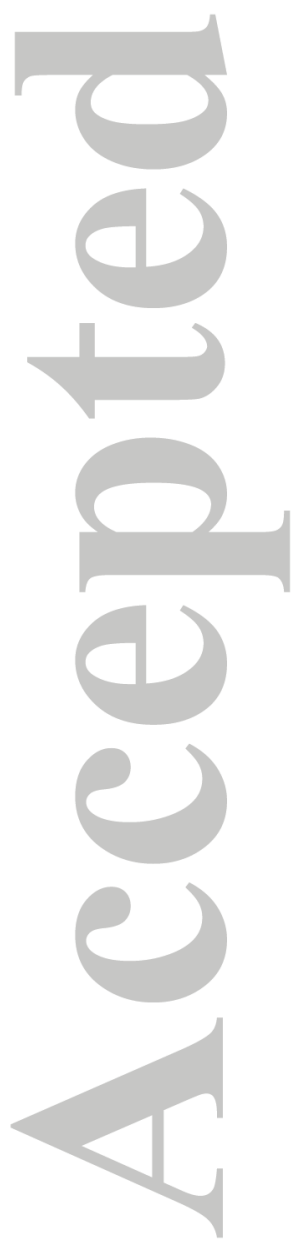




\section{Discussion}

The ability of GBS to bind blood Plg is essential for its invasiveness, in particular in promoting invasion of brain endothelial cells in vitro and of the central nervous system in vivo (Magalhaes et al., 2007, Magalhaes et al., 2013). As most pathogenic streptococci, this bacterium expresses a broad repertoire of unrelated Plg binding proteins whose biological function is, therefore, often difficult to predict. Up to now, two Plg-binding surface proteins have been extensively characterized in GBS, the GAPDH (Seifert et al., 2003, Magalhaes et al., 2007) and the cell wall-anchored LPXTG protein Srr2 (Seo et al., 2013; Six et al., 2015). The GADPH is an abundant cytoplasmic protein, essential for bacterial growth in glucosecontaining media (e.g. the blood), which is released upon cell lysis and reassociated to the surface of living cells (Oliveira et al., 2012, Madureira et al., 2011). Extracellular GBS GAPDH serves as a receptor for numerous ligands, including Plg and Fg (Seifert et al., 2003, Magalhaes et al., 2013), and exerts immunomodulatory functions (Oliveira et al., 2012, Madureira et al., 2011). This highly conserved protein was detected at the surface of GBS isolates belonging to the main phylogenetic lineages. In contrast, the Srr2 glycoprotein, an LPXTG cell wall protein, is specific for GBS strains that belong to the hypervirulent complex CC17 (Six et al., 2015) and are strongly associated with invasive neonatal meningitis. Moreover, this dual surface adhesin efficiently binds Fng and Plg (Seo et al., 2013; Six et al., 2015). While GAPDH and Srr2 are structurally unrelated, they both interact with Plg in a reaction inhibited by $6-\mathrm{ACA}$, suggesting an interaction between lysine residues within the adhesins and the lysine binding sites of the Plg Kringle domains.

Thus, the surface protein $\mathrm{PbsP}$ is the second LPXTG adhesin mediating Plg binding characterized so far in GBS. As opposed to Srr2, this protein is expressed by human clinical

isolates belonging to unrelated $\mathrm{CC}$, including the $\mathrm{CC} 17$. PbsP belongs to a family of evolutionarily-related streptococcal surface proteins containing a variable number of an 
approximately 150-aa long repeated domain designated "Streptococcal surface repeat domain" (Bumbaca et al., 2004). SSURE-containing proteins were initially characterized in $S$. pneumoniae and shown to mediate binding to both Fnt and Plg (Papasergi et al., 2010). These binding activities are mediated by the SSURE repeats and the binding efficiency apparently reflects the number of repeats (Papasergi et al., 2010, Jensch et al., 2010). In pneumococci, the SSURE-containing protein PfbB (also known as PavB) is involved in bacterial adherence to human epithelial cells, nasopharyngeal colonization, and airways infections (Jensch et al., 2010, Papasergi et al., 2010). The number of SSURE domains within PfbB varies from 2 to 6 depending on the pneumococcal strain considered and sequence analysis revealed that these repeats clustered in two main groups displaying approximately $75 \%$ of identity: the conserved first repeats (100\% of identity) and the core plus last repeats ( $>96 \%$ of identity) (Jensch et al., 2010) (Fig. S2). All human GBS isolates apparently express a highly conserved 521-aa PbsP adhesin ( $>98 \%$ identity) possessing a similar structure as the pneumococcal $\mathrm{PfbB}$, but containing only two SSURE domains that display $77 \%$ of identity and cluster apart from the pneumococcal SSURE sequences (Fig. S2). These structural differences may explain the functional differences observed between the GBS and the pneumococcal adhesins, PbsP mediating binding only to Plg whereas PfbB interacting with both Plg and Fnt.

Although differing in sequence and structure, a constant feature of bacterial and eukaryotic Plg binding motifs is the presence of positively charged amino acids in a hydrophobic surrounding (Fulde et al 2013). The SSURE domains of PbsP and PfbB are lysine-rich $(21>\mathrm{n}$ $>15$ ) and the interaction of the two proteins with Plg is inhibited by lysine. This suggests that the SSURE domains of both proteins is involved in Plg binding. However, the GBS PbsP contains a MK-rich domain that is absent in the pneumococcal protein PfbP and in vitro binding assays with purified domains demonstrated that this MK-rich domain displays a higher ability to bind Plg compared to the SSURE domains. Thus, it is likely that Plg binding 
by $\mathrm{PfbB}$ is mediated by the SSURE domains whereas both the SSURE and the additional MK-rich domains of PbsP are involved in this reaction.

Bound Plg is a substrate for activating factors and this activation results in a dramatic increase of the cell surface proteolytic activity, thereby enhancing the ability of the bacteria to degrade host physiological barriers such as the extracellular matrix, the basement membrane, and encapsulating fibrin network. In the case of GBS, this activation is mediated by the host factors tPA and uPA, while this bacterium secretes the protein Skizzle which stabilizes Plg in a cleavable conformation (Wiles et al., 2010). FACS analysis and measurement of tPAdependent surface proteolytic activity revealed that a GBS NEM316 mutant lacking PbsP binds less Plg and is less proteolytic, compared to the WT strain, although both phenotypes are not abolished. The remaining binding activity is likely due to the Plg-binding properties of the moonlighting GAPDH and phosphoglycerate kinase proteins (Seifert et al., 2003, Magalhaes et al., 2007, Boone et al., 2011). However, our results identify PbsP as a major Plg binding protein in non-CC17 GBS strains (Six et al., 2015).

PbsP expression in GBS is repressed by CovRS (Papasergi et al., 2013; Fig.2), the major global regulator of virulence gene expression (Firon et al., 2013, Lamy et al., 2004, Lembo et al., 2010, Jiang et al., 2008). While the activity of the PbsP promoter (Rosinski-Chupin et al., 2015 ) is significantly (15-fold) increased in NEM316 $\Delta \operatorname{cov} R$ mutant, as determined by using a lacZ-fusion, we failed to demonstrate the binding of CovR to the promoter region of $p b s P$, suggesting that this regulation is indirect (data not shown). Inactivation of CovR increases GBS adherence to a variety of cells and matrix components due to the deregulated expression of several adhesins (Lembo et al., 2010, Park et al., 2012, Patras et al., 2013). Our results show that $\mathrm{PbsP}$ is required for invasion and transmigration across brain endothelial cells (Fig. 6 and 7). It is therefore probable that $\mathrm{PbsP}$ expression is up regulated in vivo, together with other adhesins, by a CovR-dependent pathway, to synergistically contribute to the 
attachement to endothelial cells and blood brain barrier penetration (Lembo et al., 2010). As a conserved and cell surface localized adhesin, $\mathrm{PbsP}$ is an interesting candidate as a component of anti-GBS vaccines. Indeed, PbsP immunization protects mice from invasive infections of the central nervous system by the NEM316 strain.

In conclusion, we reported that $\mathrm{PbsP}$ is a conserved GBS cell-wall adhesins with a major role in Plg binding and a possible vaccine candidate against GBS infections. Further detailed studies are necessary to confirm PbsP function during invasive infections by unrelated GBS strains, in particular CC17 strains, and to unravel the coordinated mechanisms used by GBS to successfully hijack the host Plg/Pln fibrinolysis system.

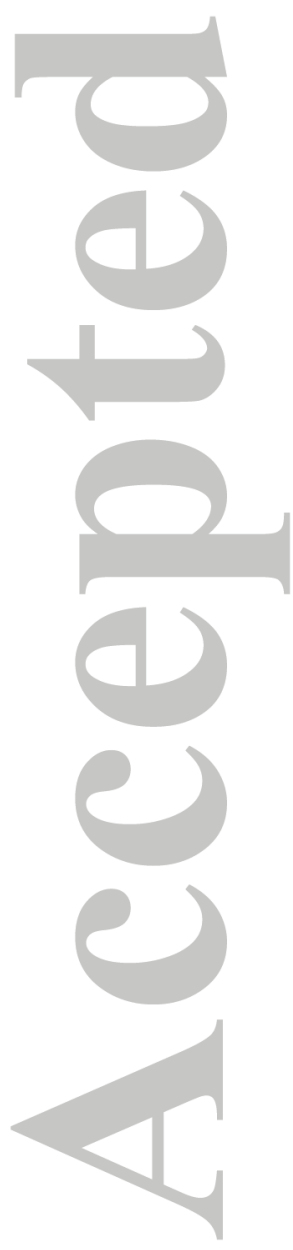




\section{Experimental procedures}

\section{Bacterial Strains and Reagents}

The following reference GBS strains were used: NEM316 (serotype III, CC23), 6313 (serotype III, CC 23), BM110 (serotype III, CC17), COH1 (serotype III, CC17), A909 (serotype Ia, CC1), and 2603V/R (serotype V, CC19) (Da Cunha et al., 2014, Glaser et al., 2002, Tettelin et al., 2005). The relevant characteristics of the other bacterial strains and plasmids used in this study are summarized in Table 1 . GBS were grown at $37^{\circ} \mathrm{C}$ in ToddHewitt (TH) broth (Difco Laboratories). Antibiotics (Sigma-Aldrich) were used at the following concentrations for Escherichia coli: ticarcillin, $100 \mu \mathrm{g} / \mathrm{ml}$; erythromycin, 150 $\mu \mathrm{g} / \mathrm{ml}$; kanamycin, $25 \mu \mathrm{g} / \mathrm{ml}$; and for GBS: erythromycin, $10 \mu \mathrm{g} / \mathrm{ml}$; kanamycin, $500 \mu \mathrm{g} / \mathrm{ml}$. Human Fnt, Plg and C Reactive Protein (Calbiochem), Factor H, Factor I, Factor B, C1q and C3 (Complement Technologies) and Collagen (Sigma-Aldrich) were purchased and Fng was prepared as previously described (Pietrocola et al., 2005).

\section{DNA manipulation and mutant construction}

Purification of GBS genomic DNA and E. coli plasmid DNA were performed with the DNeasy Blood and Tissue kit and the Quiaprep Spin Minipreps kit (Qiagen), respectively. Oligonucleotides were provided by Eurofins MWG Operon or Sigma-Aldrich and are listed in Table 2. Analytical PCR used standard Taq polymerase (Invitrogen, Life Technologies). Preparative PCR for cloning and PCR for sequencing (GATC Biotech) were carried out with a high-fidelity polymerase (MyFi or Phusion DNA polymerase, Bioline and ThermoScientific, respectively). The pG1_ $\triangle p b s P$ vector used for $p b s P$ deletion was constructed as described (Firon et al., 2013) using a splicing by overlap extension method (Heckman \& Pease, 2007) with primers pAF375_EcoRI + pAF376__0428 and pAF377_ $\Delta 0428+$ pAF378_BamHI. After GBS transformation with pG1_ $\Delta p b s P$ and selection of pG1_ $\triangle p b s P$ integration and de-recombination events, marker-less deletion of $p b s P$ was 
confirmed on genomic DNA with primers pAF379 + 380 (positive PCR product in case of $p b s P$ deletion) and pAF381 +382 (positive PCR product in case of a WT $p b s P$ gene). Primers pAF553_BamHI + pAF554_PstI were used to amplify the full-lenght pbsP gene with its predicted Shine-Dalgarno sequence from NEM316 WT genomic DNA. The PCR product was cloned into the pTCV_P $\mathrm{P}_{\text {tet }}$ vector at the corresponding restriction sites to give the constitutive $p b s P$ expressing vector $\mathrm{pTCV} \mathrm{P}_{\text {tet_}} p b s P$. The full length insert was sequenced to confirm the absence of mutations. The pTCV_P $\mathrm{P}_{\text {tet } \_p s} p$ plasmid was introduced in GBS by electroporation and transformants were selected on TH agar supplemented with kanamycin.

\section{Production of recombinant rPbsP and rPbsP domains}

Recombinant PbsP (rPbsP) was produced as described (Garibaldi et al., 2010, Papasergi et al., 2010, Buscetta et al., 2014). Briefly, the $p b s P$ gene was amplified using primers gbs0428_BamHI and gbs0428_NotI (Table 2) and cloned into the pGEX-SN bacterial expression vector (Cardaci et al., 2012). The corresponding pGEX-SN_PbsP allows the expression of the rPbsP fused to a glutathione S-transferase (GST) tag at its amino-terminal end. To produce recombinant $\mathrm{PbsP}$ fragments, the corresponding gene regions were amplified using the following primers: MK-rich 423 up and MK-rich 492 low (rMK-rich); SSURE $_{123}$ up and $\mathrm{SSURE}_{422}$ low (rSSURE.1+2); $\mathrm{SSURE}_{273}$ up and SSURE 422 low (rSSURE-2) (Table 2).

Amplified fragments containing att recombination sequences were used to transform the pDEST15 vector by Gateway cloning according to the manufacturer's instructions (Thermo Fisher Scientific). The resulting plasmids pDEST15_MK-rich, pDEST15_SSURE ${ }_{1+2}$, and pDEST15_SSURE 2 were used to transform E. coli BL21 (DE3). After induction, the recombinant fusion proteins were purified from the cytoplasm of bacterial cells using affinity chromatography (Papasergi et al., 2010). Recombinant GST was produced and purified using

the same method and used as a negative control.

\section{Production of Anti-PbsP Antisera}


CD1 mice (5 weeks old, Charles River Labs) were injected intraperitoneally with $20 \mu \mathrm{g}$ of rPbsP or GST (in a total volume of $0.2 \mathrm{ml}$ ) in complete (first injection, day 0 ) or incomplete (second and third injections on days 14 and 28, respectively) Freund's adjuvant emulsions. The use of complete Freund's adjuvant in the first immunization was justified by our previous observations that high-titer sera were more consistently obtained with this adjuvant. However, cares were taken to minimize discomfort to the animals by injecting a low volume $(0.1 \mathrm{ml}$, containing $0.05 \mathrm{mg}$ of mycobacteria) of the oily component of the emulsion. Under these conditions, no significant abdominal distension or other complications at the injection site were observed throughout the experimental period. The mice were bled at 2 weeks after the last immunization, and the sera were tested for reactivity to the purified antigen using ELISA and Western blot assays.

\section{Bacterial extracts and immunoblots}

Cell wall extracts were prepared by digestion with mutanolysin (Sigma-Aldrich) of bacterial cells grown to the exponential phase in an osmo-protective buffer, as described (Lalioui et al., 2005, Garibaldi et al., 2010). A total of $30 \mu \mathrm{g}$ of cell wall proteins (Bradford assay) were run on gels (SDS-PAGE), transferred to nitrocellulose membranes and hybridizations were performed with mouse anti-PbsP serum followed by horseradish peroxidase conjugated goat anti-mouse IgG (R \& D Systems). Loading controls consisted of parallel Coomassie-stained gels.

For Far Western analyses, Plg $(10 \mu \mathrm{g})$ was run on $12 \%$ acrylamide gels, transferred on nitrocellulose, and overlaid with $0.15 \mu \mathrm{M}$ rPbsP or GST in $1 \%$ of nonfat dry milk supplemented with $0.05 \%$ Tween 20 . Complex formation was detected using goat anti-GST $\operatorname{IgG}(1: 4,000:$ GE Healthcare) followed by alkaline phosphatase-conjugated anti-goat IgG $(1: 5,000)$ (Sigma-Aldrich). rPbsP or GST $(0.15 \mu \mathrm{M})$ were run on $12 \%$ acrylamide gels, transferred on nitrocellulose, and overlaid with Plg $(1 \mu \mathrm{g} / \mathrm{ml})$. Complex formation was 
detected using anti-Plg rabbit polyclonal antibody $(1: 5,000)$ and horseradish peroxidaseconjugated goat anti-rabbit IgG (1 :10,000; Amersham Biosciences).

\section{ELISA binding assays}

Binding of $\mathrm{PbsP}$ to host proteins (extracellular matrix or complement components) was determined using ELISA assays. Microplates coating was done with purified proteins $(100 \mu 1$ of $2 \mu \mathrm{g} / \mathrm{ml}$ solutions in $0.1 \mathrm{M}$ carbonate buffer, $\mathrm{pH} 9.0$ ) overnight at $4^{\circ} \mathrm{C}$. Blocking of the wells was done for one hour at $22^{\circ} \mathrm{C}$ with $200 \mu$ of $2 \%$ bovine serum albumin (BSA, SigmaAldrich) in PBS, followed by addition of $0.15 \mu \mathrm{M} \mathrm{rPbsP}$ or GST for one hour, and incubation with goat anti-GST (diluted 1:10,000 in PBS 0.1\% BSA) for 90 min and the secondary antigoat IgG (diluted 1:1,000) for one hour. The peroxydase substrate ophenylenediaminedihydrochloride was used to reveal bound $\mathrm{rPbsP}$ by measuring absorbance at $490 \mathrm{~nm}$ and by substracting the values obtained with the GST control. For competitive ELISA, plates coated as above with $\mathrm{Plg}$ were incubated for $1 \mathrm{~h}$ at $\mathrm{RT}$ with $\mathrm{rPbsP}(0.15 \mu \mathrm{M})$ in the presence of 0 to $300 \mathrm{mM}$ aminocaproic acid (6-ACA), L-Lysine, or L-Alanine (SigmaAldrich).

\section{Plg activation assays.}

Wells coated with rPbsP or GST $(10 \mu \mathrm{g} / \mathrm{ml})$ were incubated with Plg $(2 \mu \mathrm{g} /$ well $)$ in $100 \mathrm{mM}$ HEPES (pH 7.4), 100 mM NaCl, 1 mM EDTA and 1 mg/ml PEG 8000 (Sigma-Aldrich) for $1.5 \mathrm{~h}$ at RT. After extensive washing, $5 \mathrm{nM}$ tPA (tissue plasminogen activator) (SigmaAldrich) was added and plasmin activity was quantified with the chromogenic substrate S-

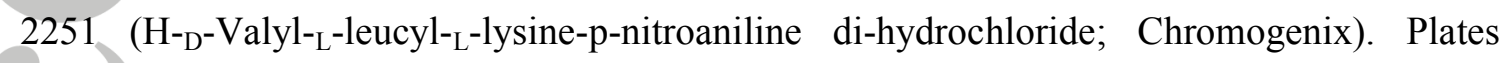
were incubated at $37^{\circ} \mathrm{C}$, and absorbance at $415 \mathrm{~nm}$ was used to quantify cleavage of the chromogenic substrate.

\section{Fibrinogen degradation assay.}

Microtiter plates were coated with $100 \mu 1$ of $\mathrm{rPbsP}$ or GST $(0.15 \mu \mathrm{M})$ overnight in $0.1 \mathrm{M}$ 
carbonate buffer, $\mathrm{pH} 9.0$, at $4^{\circ} \mathrm{C}$. Blocking was performed with $200 \mu 1$ of $\mathrm{PBS}+5 \%$ of BSA for $1 \mathrm{~h}$ at RT. Plasminogen $(10 \mu \mathrm{g} / \mathrm{ml})$ diluted in $100 \mathrm{mM}$ HEPES, $\mathrm{pH} 7.4,100 \mathrm{mM} \mathrm{NaCl}, 1$ mM EDTA, $1 \mathrm{mg} / \mathrm{ml}$ PEG 8000 was incubated with immobilized rPbsP or GST for $90 \mathrm{~min}$ at RT. After washing, fibrinogen $(10 \mu \mathrm{g} /$ well $)$ together with tPA $(5 \mathrm{nM})$ were added to the wells and the mixtures incubated at $37^{\circ} \mathrm{C}$ for the indicated time points. The reaction was stopped by the addition of reducing SDS-PAGE sample buffer and boiling at $95^{\circ} \mathrm{C}$ for $5 \mathrm{~min}$. Thereafter, the samples were separated by SDS-PAGE and the degradation of Fng was evaluated by Coomassie blue staining.

\section{Surface plasmon resonance}

Surface plasmon resonance (SPR) measurements were carried out on a Biacore X-100 instrument (GE Health-care, Piscataway, NJ, USA). To measure $\mathrm{K}_{D}$ values of plasminogen binding to recombinant $\mathrm{rPbsP}$, goat anti-GST antibody $(30 \mu \mathrm{g} / \mathrm{ml})$, dissolved in $10 \mathrm{mM}$ sodium acetate buffer $(\mathrm{pH} 5.0)$, was immobilized onto a carboxy-derivatized sensor chip (CM5). rPbsP (500 nM) was passed over a flow cell, whereas GST alone was passed in a reference cell. Human plasminogen was flowed over the surface of both flow cells at increasing concentrations ranging from 0.4 to $4 \mu \mathrm{M}$ at a rate of $10 \mu \mathrm{l} / \mathrm{min}$. Assay channel data was subtracted from reference flow cell data to eliminate the effects of nonspecific interactions. The response units (RU) at steady state were plotted as a function of Plg concentration, and fitted to the Langmuir equation to yield the $\mathrm{K}_{D}$ of the $\mathrm{Plg}-\mathrm{rPbs} \mathrm{P}$ interaction.

\section{Flow Cytometry analysis}

Binding of plasminogen or anti-PbsP antibodies to the bacterial cell surface was visualized using flow cytometry immunofluorescence analysis, as previously described (Buscetta et al.,

2014). Briefly, GBS strains grown to the log phase in TH were washed in PBS, fixed with $3.7 \%$ formaldehyde, and blocked using PBS supplemented with $1 \%$ dry milk (mPBS). For 
plasminogen-binding studies, bacteria were sequentially incubated with plasminogen (at a final concentration of $0.5 \mathrm{mg} / \mathrm{ml}$ in $\mathrm{mPBS}$ ) and with an anti-plasminogen rabbit polyclonal antibody (diluted 1:1,000 in 1\% mPBS). After washing with PBS, bacteria were then treated with FITC-conjugated goat anti-rabbit IgG (Sigma-Aldrich) diluted 1:1,000 in 1\% mPBS. To visualize surface-expressed PbsP, bacteria were incubated with anti-rPbsP or anti-GST serum diluted 1:250 followed by FITC- or phycoerythrin-conjugated goat anti-mouse IgG (diluted 1:1,000 or 1:200, respectively; Sigma-Aldrich), as described (Boone et al., 2011, Cardaci et al., 2012). Fluorescent bacteria were analyzed with a MACS Quant VYB, FACSCantoII flow cytometer using the FlowJo software (BD Biosciences).

\section{Plasminogen activation by GBS}

The ability of GBS to activate Plg into plasmin was monitored in a quantitative assay using the chromogenic substrate D-Val-Leu-Lys-p-nitroanilide (Sigma-Aldrich). Approximately $5 \mathrm{x}$ $10^{8}$ bacteria were washed with PBS, blocked for 20 min with $1 \%$ milk in PBS, mixed with Plg $(0.5 \mathrm{mg} / \mathrm{ml})$ in the presence or absence of human tissue-type plasminogen activator (tPA: 20 $\mathrm{nM})$ (Sigma-Aldrich) and incubated for $2 \mathrm{~h}$ at $37^{\circ} \mathrm{C}$. After incubation, the cells were centrifuged, washed, and re-suspended in $400 \mu \mathrm{l}$ of chromogenic substrate D-Val-Leu-Lys-pnitroanilide $\left(400 \mu \mathrm{M}\right.$ final concentration). After $12 \mathrm{~h}$ incubation at $37^{\circ} \mathrm{C}$, the cells were pelleted and the absorbance of $100 \mu$ of the supernatant fluid was measured at $405 \mathrm{~nm}$ in a microplate reader. The $12 \mathrm{~h}$ incubation time was chosen, because is representative of the kinetics of this reaction, as determined in previous studies (Megalhaes et al. 2007, Megalhaes et al. 2013, Six et al. 2015).

\section{Adhesion and Invasion}

The human brain endothelial cell line hCMEC/D3 was provided by P.O. Couraud (INSERM, Paris, France) and the adherence and invasion assays were performed as described (Buscetta et al., 2014, Weksler et al., 2005). Briefly, bacteria were grown to the mid-log phase and 
added to confluent monolayers at a multiplicity of infection (MOI) of 10 bacteria/cell. After one hour incubation, monolayers were washed with PBS to remove non-adherent bacteria, lysed, and plated to enumerate cell-associated bacteria. For the invasion assay, after washing, the monolayers were further incubated for $1 \mathrm{~h}$ with medium supplemented with penicillin and streptomycin (200 units $/ \mathrm{ml}$ and $200 \mu \mathrm{g} / \mathrm{ml}$, respectively) to kill extracellular bacteria. Percentages of bacterial adhesion and invasion were calculated as recovered cfu/initial inoculum cfu x 100.

\section{GBS migration assay across hBMEC}

An endothelial blood-brain barrier in vitro model was established by cultivating hCMECs on collagen-coated polycarbonate transwell membrane inserts with a pore size of $3 \mu \mathrm{m}$ (Corning). This in vitro model allows separate access to the upper chamber (blood side) and lower chamber (brain side) and mimics GBS penetration into the brain. The hCMEC monolayer was grown by seeding $500 \mu 1$ of growth medium containing $1 \times 10^{6}$ cells in the upper channel and $1.5 \mathrm{ml}$ growth medium in the bottom chamber of 12 wells tissue culture inserts. The hCMEC were grown for 5 to 7 days at $37^{\circ} \mathrm{C}$ in a humidified chamber containing $5 \% \mathrm{CO}_{2}$ to reach confluence. Only monolayers with a trans-endothelial electric resistance (TEER) greater than $200 \mathrm{ohm} \cdot \mathrm{cm}^{-2}$ were used, as measured with a Millicell ERS-2 meter (Millipore). Prior to the assay, hCMECs were washed and resuspended in serum-free culture medium without antibiotics. Log-phase GBS cells untreated or treated with a final concentration of human Plg/Pln of $50 \mu \mathrm{g}$ plus tPA $(20 \mathrm{nM})$ were applied to the apical chamber (total volume of $500 \mu \mathrm{l}$ with a MOI of 10). At $2 \mathrm{~h}$ post-infection, the lower chamber medium was entirely removed and plated onto $\mathrm{TH}$ agar to enumerate bacteria crossing the hCMEC monolayer. Simultaneously, the integrity of the hCMEC monolayer was assessed by

TEER measurement.

\section{Animals model of GBS infection.}


All studies involving mice were performed in strict accordance with the European Union guidelines for the use of laboratory animals. The procedures were approved by the Ethics Committee of the University of Messina (OPBA permit no. 18052010) and by the Ministero della Salute of Italy (permit no. 665/2015).

Virulence of GBS strains were tested with 8 week-old CD1 mice infected intravenously (i.v.) with $5 \times 10^{8}$ bacteria, as described (Buscetta et al., 2014). Mice were monitored at least once a day for lethality and signs of disease for a total of 14 days after challenge, as described (Garibaldi et al., 2010, Cardaci et al., 2012). Animals with signs of irreversible sepsis were euthanized and GBS invasion of organs confirmed as the cause of disease. In a second set of experiments, GBS-infected mice were sacrificed at $48 \mathrm{~h}$ after infection to collect blood, brains and kidneys. The number of CFU was measured in organ homogenates using standard methods (Cardaci et al., 2012). To study the protective effet of PbsP immunization, CD1 mice (5 weeks old, Charles River Labs) were injected intraperitoneally (i.p.) with $20 \mu \mathrm{g}$ of rPbsP or GST in complete (first injection) or incomplete (second and third injections) Freund's adjuvant emulsions (in a total volume of $0.2 \mathrm{ml}$ ) on day 0,14 , and 28 . Three weeks after the last immunization, mice were challenged i.v. with $2 \times 10^{8}$ CFUs of the NEM316 WT strain.

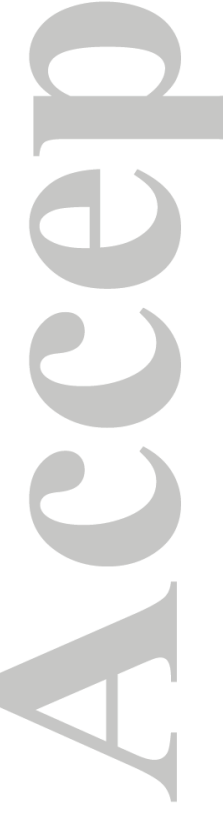




\section{Acknowledgements}

Work described here was supported in part by funds granted to Scylla Biotech Srl by the Ministero dell’Università e della Ricerca Scientifica of Italy (Project n.4/13 ex art. 11 D.M. n. 593). This work was also supported by the Institut Pasteur, CNRS, French Government's Investissement d'Avenir program, Laboratoire d'Excellence "Integrative Biology of Emerging Infectious Diseases" (Grant ANR-10-LABX-62-IBEID), and Fondation pour la Recherche Médicale (Grant DEQ20130326538).
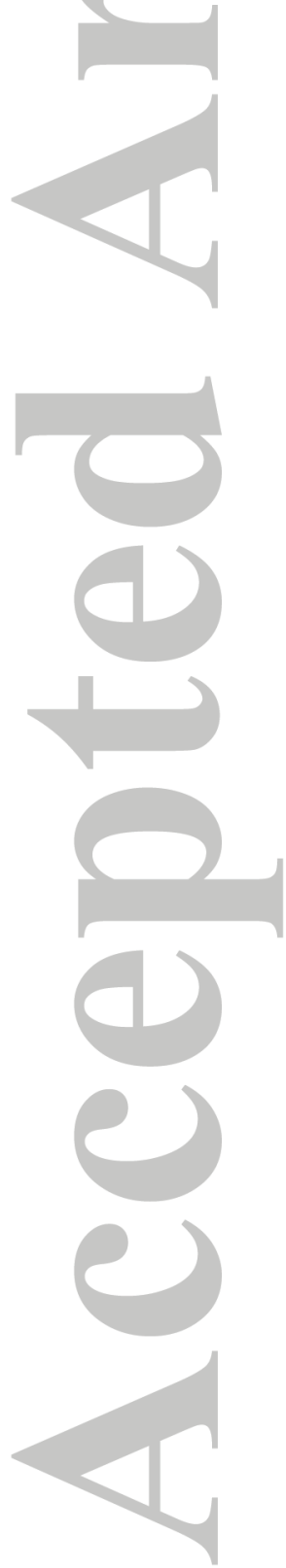


\section{References}

Bergmann, S. \& S. Hammerschmidt, (2007) Fibrinolysis and host response in bacterial infections. Thrombosis and haemostasis 98: 512-520.

Boone, T.J., C.A. Burnham \& G.J. Tyrrell, (2011) Binding of group B streptococcal phosphoglycerate kinase to plasminogen and actin. Microbial pathogenesis 51: 255261.

Boone, T.J. \& G.J. Tyrrell, (2012) Identification of the actin and plasminogen binding regions of group B streptococcal phosphoglycerate kinase. J Biol Chem 287: 29035-29044.

Brega, S., E. Caliot, P. Trieu-Cuot \& S. Dramsi, (2013) SecA localization and SecAdependent secretion occurs at new division septa in group B Streptococcus. PloS one 8: e65832.

Brochet, M., E. Couve, M. Zouine, T. Vallaeys, C. Rusniok, M.C. Lamy, C. Buchrieser, P. Trieu-Cuot, F. Kunst, C. Poyart \& P. Glaser, (2006) Genomic diversity and evolution within the species Streptococcus agalactiae. Microbes and infection 8: 1227-1243.

Bumbaca, D., J.E. Littlejohn, H. Nayakanti, D.J. Rigden, M.Y. Galperin \& M.J. Jedrzejas, (2004) Sequence analysis and characterization of a novel fibronectin-binding repeat domain from the surface of Streptococcus pneumoniae. Omics : a journal of integrative biology 8: 341-356.

Buscetta, M., S. Papasergi, A. Firon, G. Pietrocola, C. Biondo, G. Mancuso, A. Midiri, L. Romeo, G. Teti, P. Speziale, P. Trieu-Cuot \& C. Beninati, (2014) FbsC, a novel fibrinogen-binding protein, promotes Streptococcus agalactiae-host cell interactions. $J$ Biol Chem 289: 21003-21015.

Cardaci, A., S. Papasergi, A. Midiri, G. Mancuso, M. Domina, V.L. Cariccio, F. Mandanici, R. Galbo, C. Lo Passo, I. Pernice, P. Donato, S. Ricci, C. Biondo, G. Teti, F. Felici \& 
C. Beninati, (2012) Protective activity of Streptococcus pneumoniae Spr1875 protein fragments identified using a phage displayed genomic library. PloS one 7: e36588.

Carlsson, F., M. Stalhammar-Carlemalm, K. Flardh, C. Sandin, E. Carlemalm \& G. Lindahl, (2006) Signal sequence directs localized secretion of bacterial surface proteins. Nature 442: $943-946$.

Da Cunha, V., M.R. Davies, P.E. Douarre, I. Rosinski-Chupin, I. Margarit, S. Spinali, T. Perkins, P. Lechat, N. Dmytruk, E. Sauvage, L. Ma, B. Romi, M. Tichit, M.J. LopezSanchez, S. Descorps-Declere, E. Souche, C. Buchrieser, P. Trieu-Cuot, I. Moszer, D. Clermont, D. Maione, C. Bouchier, D.J. McMillan, J. Parkhill, J.L. Telford, G. Dougan, M.J. Walker, D. Consortium, M.T. Holden, C. Poyart \& P. Glaser, (2014) Streptococcus agalactiae clones infecting humans were selected and fixed through the extensive use of tetracycline. Nature communications 5: 4544.

Edmond, K.M., C. Kortsalioudaki, S. Scott, S.J. Schrag, A.K. Zaidi, S. Cousens \& P.T. Heath, (2012) Group B streptococcal disease in infants aged younger than 3 months: systematic review and meta-analysis. Lancet 379: 547-556.

Firon, A., A. Tazi, V. Da Cunha, S. Brinster, E. Sauvage, S. Dramsi, D.T. Golenbock, P. Glaser, C. Poyart \& P. Trieu-Cuot, (2013) The Abi-domain protein Abx1 interacts with the CovS histidine kinase to control virulence gene expression in group B Streptococcus. PLoS pathogens 9: e1003179.

Foley, J.H., E.A. Peterson, V. Lei, L.W. Wan, M.J. Krisinger \& E.M. Conway, (2015) Interplay between fibrinolysis and complement: plasmin cleavage of $\mathrm{iC} 3 \mathrm{~b}$ modulates immune responses. Journal of thrombosis and haemostasis 13: 610-618.

Fulde, M., M. Steinert \& S. Bergmann, (2013) Interaction of streptococcal plasminogen binding proteins with the host fibrinolytic system. Frontiers in cellular and infection microbiology 3: 85 . 
Garibaldi, M., M.J. Rodriguez-Ortega, F. Mandanici, A. Cardaci, A. Midiri, S. Papasergi, O. Gambadoro, V. Cavallari, G. Teti \& C. Beninati, (2010) Immunoprotective activities of a Streptococcus suis pilus subunit in murine models of infection. Vaccine 28: 36093616.

Glaser, P., C. Rusniok, C. Buchrieser, F. Chevalier, L. Frangeul, T. Msadek, M. Zouine, E. Couve, L. Lalioui, C. Poyart, P. Trieu-Cuot \& F. Kunst, (2002) Genome sequence of Streptococcus agalactiae, a pathogen causing invasive neonatal disease. Molecular microbiology 45: 1499-1513.

Gutekunst, H., B.J. Eikmanns \& D.J. Reinscheid, (2004) The novel fibrinogen-binding protein FbsB promotes Streptococcus agalactiae invasion into epithelial cells. Infection and immunity 72: 3495-3504.

Hartley, J.L., G.F. Temple \& M.A. Brasch, (2000) DNA cloning using in vitro site-specific recombination. Genome Res. 10:1788-95.

Heckman, K.L. \& L.R. Pease, (2007) Gene splicing and mutagenesis by PCR-driven overlap extension. Nat Protoc 2: 924-932.

Jensch, I., G. Gamez, M. Rothe, S. Ebert, M. Fulde, D. Somplatzki, S. Bergmann, L. Petruschka, M. Rohde, R. Nau \& S. Hammerschmidt, (2010) PavB is a surfaceexposed adhesin of Streptococcus pneumoniae contributing to nasopharyngeal colonization and airways infections. Molecular microbiology 77: 22-43.

Jiang, S. \& M.R. Wessels, (2014) BsaB, a novel adherence factor of group B Streptococcus. Infection and immunity 82: 1007-1016.

Jiang, S.M., N. Ishmael, J.D. Hotopp, M. Puliti, L. Tissi, N. Kumar, M.J. Cieslewicz, H. Tettelin \& M.R. Wessels, (2008) Variation in the Group B Streptococcus CsrRS regulon and effects on pathogenicity. J Bacteriol 190: 1956-1965. 
Kline, K.A., S. Falker, S. Dahlberg, S. Normark \& B. Henriques-Normark, (2009) Bacterial adhesins in host-microbe interactions. Cell host \& microbe 5: 580-592.

Konto-Ghiorghi, Y., E. Mairey, A. Mallet, G. Dumenil, E. Caliot, P. Trieu-Cuot \& S. Dramsi, (2009) Dual role for pilus in adherence to epithelial cells and biofilm formation in Streptococcus agalactiae. PLoS pathogens 5: e1000422.

Lahteenmaki, K., P. Kuusela \& T.K. Korhonen, (2001) Bacterial plasminogen activators and receptors. FEMS microbiology reviews 25: 531-552.

Lalioui, L., E. Pellegrini, S. Dramsi, M. Baptista, N. Bourgeois, F. Doucet-Populaire, C. Rusniok, M. Zouine, P. Glaser, F. Kunst, C. Poyart \& P. Trieu-Cuot, (2005) The SrtA Sortase of Streptococcus agalactiae is required for cell wall anchoring of proteins containing the LPXTG motif, for adhesion to epithelial cells, and for colonization of the mouse intestine. Infection and immunity 73: 3342-3350.

Lamy, M.C., M. Zouine, J. Fert, M. Vergassola, E. Couve, E. Pellegrini, P. Glaser, F. Kunst, T. Msadek, P. Trieu-Cuot \& C. Poyart, (2004) CovS/CovR of group B Streptococcus: a two-component global regulatory system involved in virulence. Molecular microbiology 54: 1250-1268.

Le Doare, K. \& P.T. Heath, (2013) An overview of global GBS epidemiology. Vaccine 31 Suppl 4: D7-12.

Lembo, A., M.A. Gurney, K. Burnside, A. Banerjee, M. de los Reyes, J.E. Connelly, W.J. Lin, K.A. Jewell, A. Vo, C.W. Renken, K.S. Doran \& L. Rajagopal, (2010) Regulation of CovR expression in Group B Streptococcus impacts blood-brain barrier penetration. Molecular microbiology 77: 431-443.

Madureira, P., E.B. Andrade, B. Gama, L. Oliveira, S. Moreira, A. Ribeiro, M. CorreiaNeves, P. Trieu-Cuot, M. Vilanova \& P. Ferreira, (2011) Inhibition of IL-10 production by maternal antibodies against Group B Streptococcus GAPDH confers 
immunity to offspring by favoring neutrophil recruitment. PLoS pathogens 7: e1002363.

Magalhaes, V., E.B. Andrade, J. Alves, A. Ribeiro, K.S. Kim, M. Lima, P. Trieu-Cuot \& P. Ferreira, (2013) Group B Streptococcus hijacks the host plasminogen system to promote brain endothelial cell invasion. PloS one 8: e63244.

Magalhaes, V., I. Veiga-Malta, M.R. Almeida, M. Baptista, A. Ribeiro, P. Trieu-Cuot \& P. Ferreira, (2007) Interaction with human plasminogen system turns on proteolytic activity in Streptococcus agalactiae and enhances its virulence in a mouse model. Microbes and infection 9: 1276-1284.

Mazmanian, S.K., G. Liu, H. Ton-That \& O. Schneewind, (1999) Staphylococcus aureus sortase, an enzyme that anchors surface proteins to the cell wall. Science 285: 760763.

Mistou, M.Y., S. Dramsi, S. Brega, C. Poyart \& P. Trieu-Cuot, (2009) Molecular dissection of the secA2 locus of group B Streptococcus reveals that glycosylation of the Srr1 LPXTG protein is required for full virulence. J Bacteriol 191: 4195-4206.

Mu, R., B.J. Kim, C. Paco, Y. Del Rosario, H.S. Courtney \& K.S. Doran, (2014) Identification of a group B streptococcal fibronectin binding protein, $\mathrm{SfbA}$, that contributes to invasion of brain endothelium and development of meningitis. Infection and immunity 82: 2276-2286.

Nobbs, A.H., R.J. Lamont \& H.F. Jenkinson, (2009) Streptococcus adherence and colonization. Microbiology and molecular biology reviews : MMBR 73: 407-450, Table of Contents.

Oliveira, L., P. Madureira, E.B. Andrade, A. Bouaboud, E. Morello, P. Ferreira, C. Poyart, P. Trieu-Cuot \& S. Dramsi, (2012) Group B streptococcus GAPDH is released upon cell 
lysis, associates with bacterial surface, and induces apoptosis in murine macrophages. PloS one 7: e29963.

Papasergi, S., S. Brega, M.Y. Mistou, A. Firon, V. Oxaran, R. Dover, G. Teti, Y. Shai, P. Trieu-Cuot \& S. Dramsi, (2011) The GBS PI-2a pilus is required for virulence in mice neonates. PloS one 6: e18747.

Papasergi, S., R. Galbo, V. Lanza-Cariccio, M. Domina, G. Signorino, C. Biondo, I. Pernice, C. Poyart, P. Trieu-Cuot, G. Teti \& C. Beninati, (2013) Analysis of the Streptococcus agalactiae exoproteome. Journal of proteomics 89: 154-164.

Papasergi, S., M. Garibaldi, G. Tuscano, G. Signorino, S. Ricci, S. Peppoloni, I. Pernice, C. Lo Passo, G. Teti, F. Felici \& C. Beninati, (2010) Plasminogen- and fibronectinbinding protein B is involved in the adherence of Streptococcus pneumoniae to human epithelial cells. The Journal of biological chemistry 285: 7517-7524.

Park, S.E., S. Jiang \& M.R. Wessels, (2012) CsrRS and Environmental pH Regulate Group B Streptococcus Adherence to Human Epithelial Cells and Extracellular Matrix. Infect Immun 80: 3975-3984.

Patras, K.A., N.Y. Wang, E.M. Fletcher, C.K. Cavaco, A. Jimenez, M. Garg, J. Fierer, T.R. Sheen, L. Rajagopal \& K.S. Doran, (2013) Group B Streptococcus CovR regulation modulates host immune signalling pathways to promote vaginal colonization. Cell Microbiol 15: 1154-1167.

Pietrocola, G., A. Schubert, L. Visai, M. Torti, J.R. Fitzgerald, T.J. Foster, D.J. Reinscheid \& P. Speziale, (2005) FbsA, a fibrinogen-binding protein from Streptococcus agalactiae, mediates platelet aggregation. Blood 105: 1052-1059.

Rosinski-Chupin, I., E. Sauvage, O. Sismeiro, A. Villain, V. Da Cunha, M.E. Caliot, M.A. Dillies, P. Trieu-Cuot, P. Bouloc, M.F. Lartigue \& P. Glaser, (2015) Single nucleotide 
resolution RNA-seq uncovers new regulatory mechanisms in the opportunistic pathogen Streptococcus agalactiae. BMC genomics 16: 419.

Seifert, K.N., W.P. McArthur, A.S. Bleiweis \& L.J. Brady, (2003) Characterization of group B streptococcal glyceraldehyde-3-phosphate dehydrogenase: surface localization, enzymatic activity, and protein-protein interactions. Canadian journal of microbiology 49: $350-356$.

Seo, H.S., G. Minasov, R. Seepersaud, K.S. Doran, I. Dubrovska, L. Shuvalova, W.F. Anderson, T.M. Iverson \& P.M. Sullam, (2013) Characterization of fibrinogen binding by glycoproteins Srr1 and Srr2 of Streptococcus agalactiae. The Journal of biological chemistry 288: 35982-35996.

Six, A., S. Bellais, A. Bouaboud, A. Fouet, C. Gabriel, A. Tazi, S. Dramsi, P. Trieu-Cuot \& C. Poyart, (2015) Srr2, a multifaceted adhesin expressed by ST-17 hypervirulent Group B Streptococcus involved in binding to both fibrinogen and plasminogen. Mol Microbiol 97: 1209-1222..

Skoff, T.H., M.M. Farley, S. Petit, A.S. Craig, W. Schaffner, K. Gershman, L.H. Harrison, R. Lynfield, J. Mohle-Boetani, S. Zansky, B.A. Albanese, K. Stefonek, E.R. Zell, D. Jackson, T. Thompson \& S.J. Schrag, (2009) Increasing burden of invasive group B streptococcal disease in nonpregnant adults, 1990-2007. Clin Infect Dis 49: 85-92.

Tazi, A., O. Disson, S. Bellais, A. Bouaboud, N. Dmytruk, S. Dramsi, M.Y. Mistou, H. Khun, C. Mechler, I. Tardieux, P. Trieu-Cuot, M. Lecuit \& C. Poyart, (2010) The surface protein HvgA mediates group B streptococcus hypervirulence and meningeal tropism in neonates. The Journal of experimental medicine 207: 2313-2322.

Tettelin, H., V. Masignani, M.J. Cieslewicz, C. Donati, D. Medini, N.L. Ward, S.V. Angiuoli, J. Crabtree, A.L. Jones, A.S. Durkin, R.T. Deboy, T.M. Davidsen, M. Mora, M. Scarselli, I. Margarit y Ros, J.D. Peterson, C.R. Hauser, J.P. Sundaram, W.C. Nelson, 
R. Madupu, L.M. Brinkac, R.J. Dodson, M.J. Rosovitz, S.A. Sullivan, S.C. Daugherty, D.H. Haft, J. Selengut, M.L. Gwinn, L. Zhou, N. Zafar, H. Khouri, D. Radune, G. Dimitrov, K. Watkins, K.J. O'Connor, S. Smith, T.R. Utterback, O. White, C.E. Rubens, G. Grandi, L.C. Madoff, D.L. Kasper, J.L. Telford, M.R. Wessels, R. Rappuoli \& C.M. Fraser, (2005) Genome analysis of multiple pathogenic isolates of Streptococcus agalactiae: implications for the microbial "pan-genome". Proc Natl Acad Sci U S A 102: 13950-13955.

Wang, N.Y., K.A. Patras, H.S. Seo, C.K. Cavaco, B. Rosler, M.N. Neely, P.M. Sullam \& K.S. Doran, (2014) Group B streptococcal serine-rich repeat proteins promote interaction with fibrinogen and vaginal colonization. The Journal of infectious diseases 210: 982991.

Weksler, B.B., E.A. Subileau, N. Perriere, P. Charneau, K. Holloway, M. Leveque, H. Tricoire-Leignel, A. Nicotra, S. Bourdoulous, P. Turowski, D.K. Male, F. Roux, J. Greenwood, I.A. Romero \& P.O. Couraud, (2005) Blood-brain barrier-specific properties of a human adult brain endothelial cell line. FASEB journal : official publication of the Federation of American Societies for Experimental Biology 19: $1872-1874$.

Wiles, K.G., P. Panizzi, H.K. Kroh \& P.E. Bock, (2010) Skizzle is a novel plasminogen- and plasmin-binding protein from Streptococcus agalactiae that targets proteins of human fibrinolysis to promote plasmin generation. The Journal of biological chemistry $\mathbf{2 8 5}$ : 21153-21164. 


\section{Table 1. GBS strains}

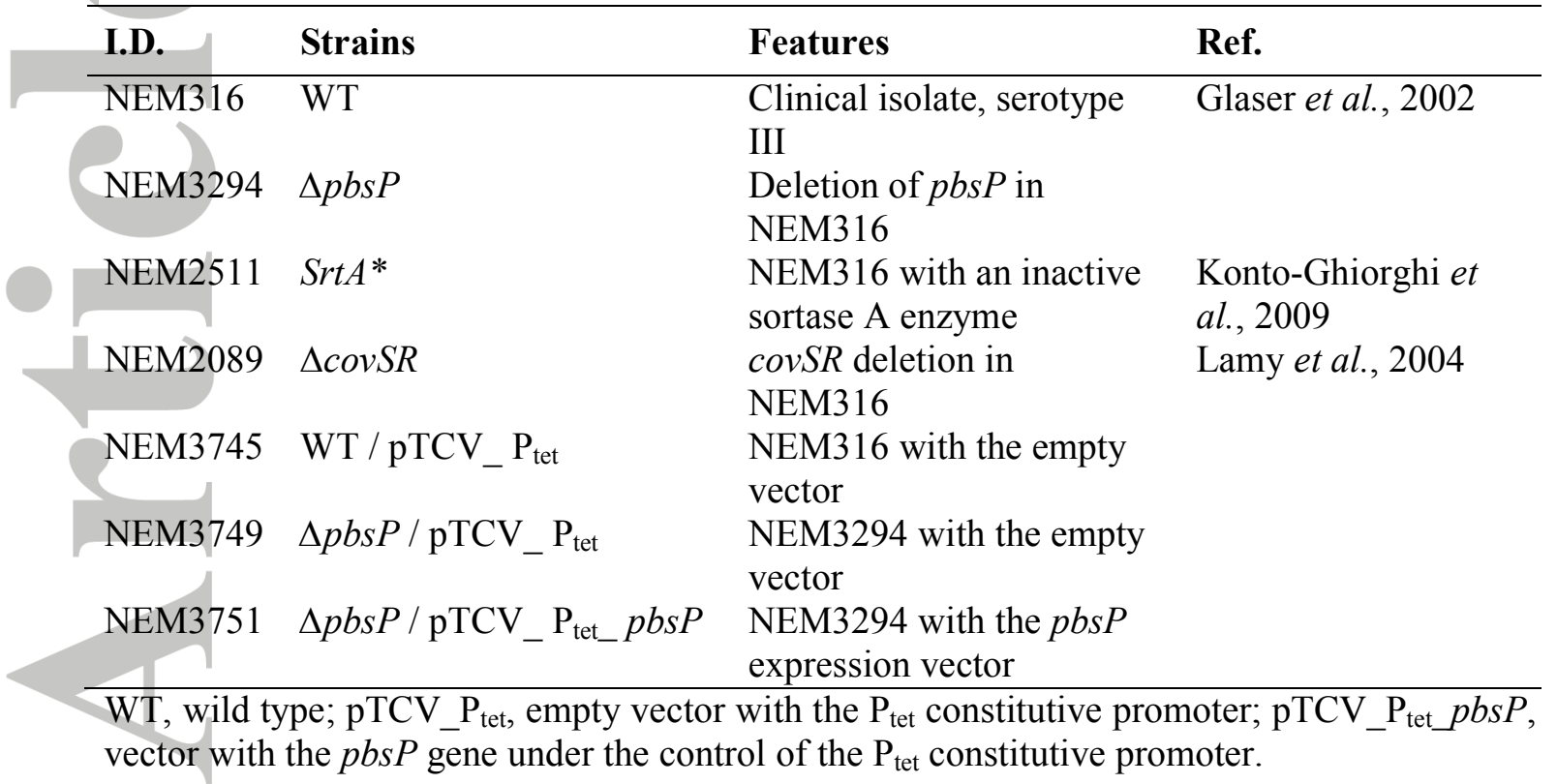

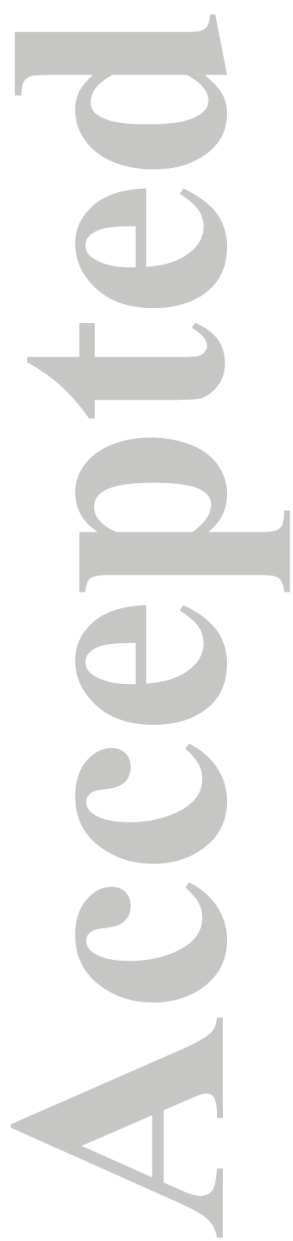


Table 2. Plasmids and oligonucleotides used in this study

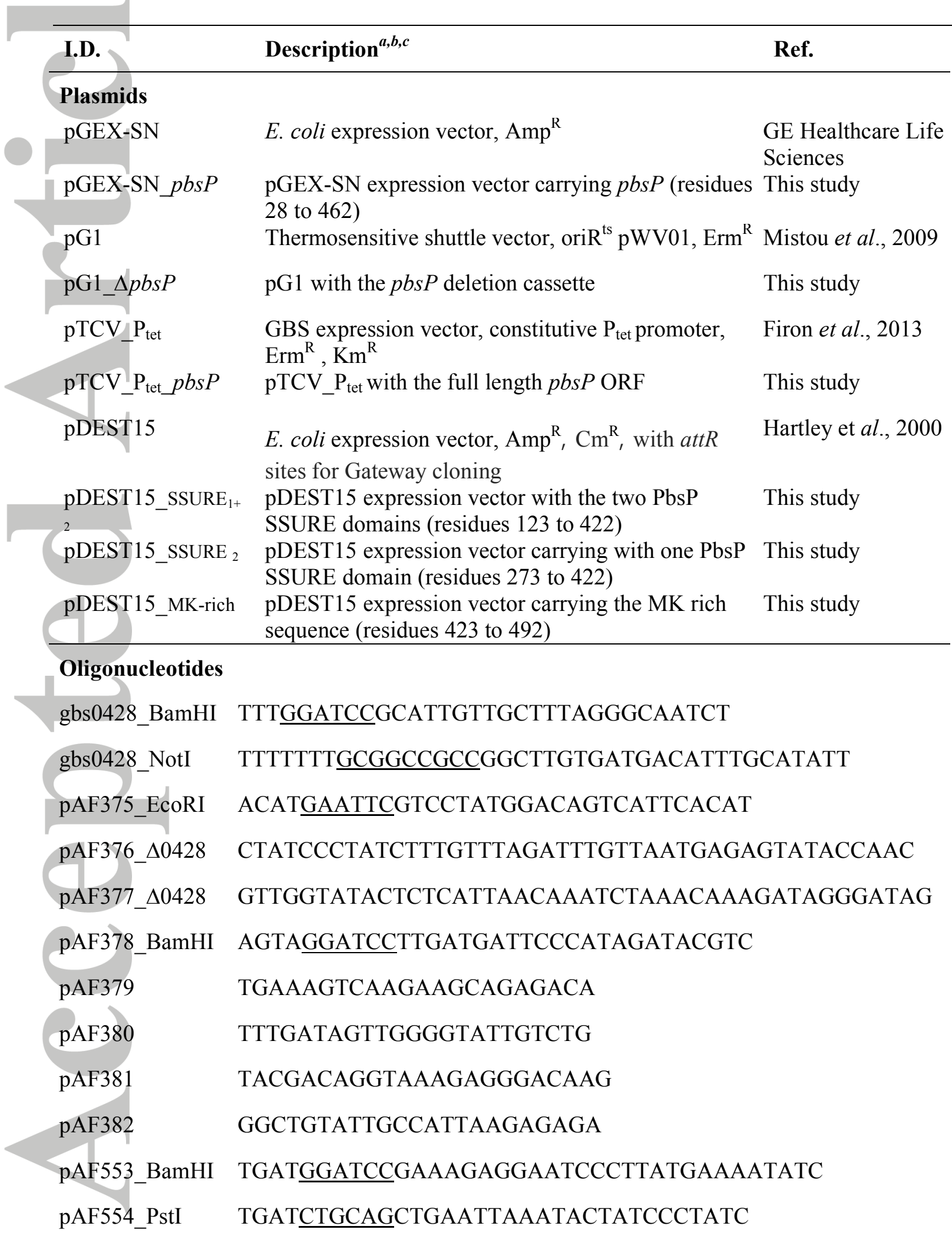




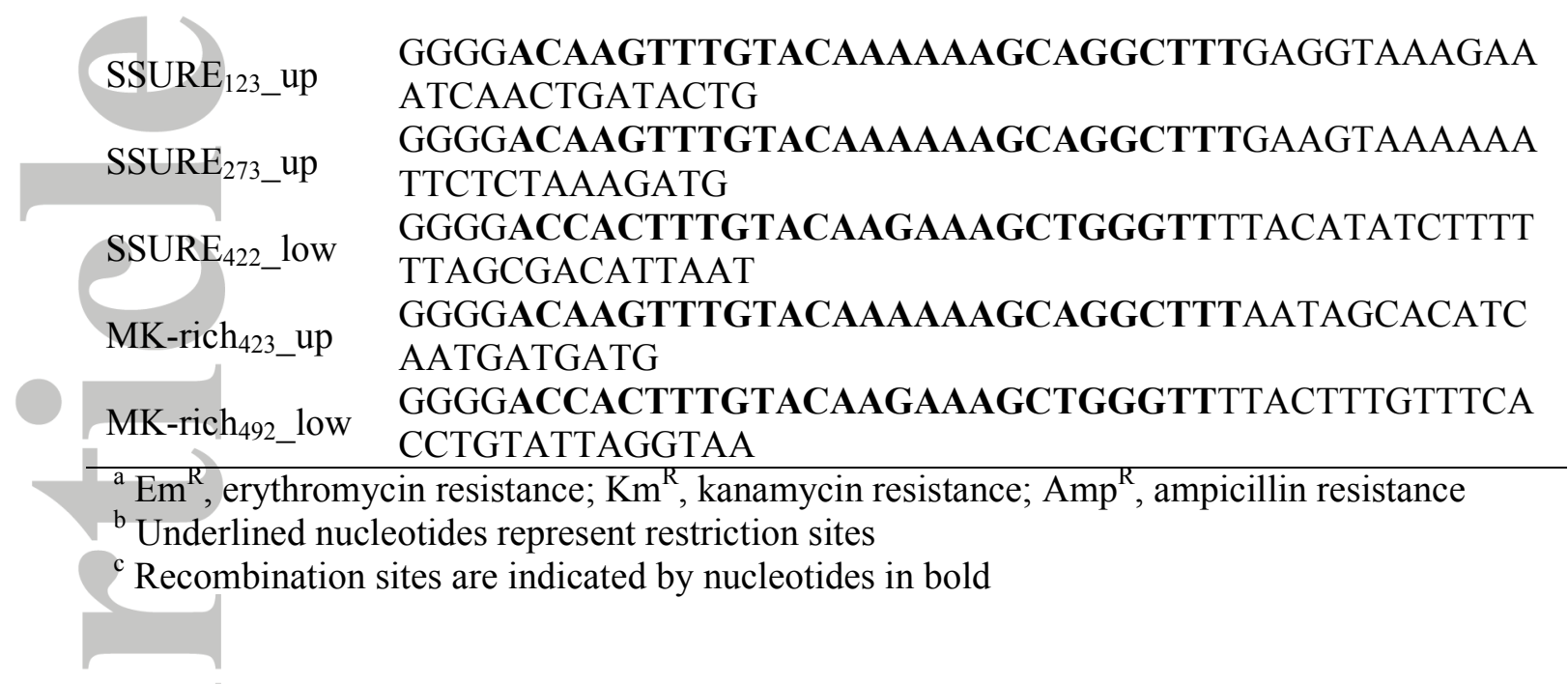




\section{Figure legends}

\section{Figure 1. PbsP is a SSURE domain-containing protein.}

A. Schematic representation of PbsP. SP, signal peptide; N-terminal, N-terminal domain; SSURE1 and SSURE2, streptococcal surface repeats 1 and 2; MK rich: methionine and lysine-rich region; LPXTG, cell wall anchoring motif.

B. Sequence alignment of the SSURE1 and SSURE2 domains. Asterisk (*), identity; colon (:), residues with strongly similar properties ( $>0.5$ in the Gonnet PAM 250 matrix); period (.) residues with weakly similar properties ( $<0.5$ in the Gonnet PAM 250 matrix).

\section{Figure 2. PbsP is a conserved cell surface protein.}

The following GBS strains were compared: WT, wild-type strain NEM316; $\Delta p b s P$, deletion mutant lacking $\mathrm{PbsP} ; s r t A^{*}$, mutant with an inactive form of sortase $\mathrm{A} ; \Delta \operatorname{cov} R S$ deletion mutant lacking the two-component system CovRS.

A. Western blot analysis of cell wall extracts. Left panel, coomassie staining of cell wall extracts separated by polyacrylamide gel electrophoresis; right panel, corresponding western blot analysis using polyclonal anti-PbsP mouse serum.

B. Expression of PbsP on the GBS surface. Immunofluorescence flow cytometry analysis of $\mathrm{Pbs} \mathrm{P}$ espression on different bacterial strains using mouse polyclonal anti-PbsP serum (blue line) or control anti-GST serum (red line). GBS wild-type strains of different serotypes and clonal complexes are indicated by their common name (6313, A909, COH1, BM110, 2603V/R).

\section{Figure 3. PbsP binds plasminogen in vitro}


A. Selective binding of $\mathrm{PbsP}$ to immobilized plasminogen. Binding of recombinant $\mathrm{Pbs} \mathrm{P}$ to immobilized human plasminogen (Plg), collagen (Coll), fibronectin (Fnt), fibrinogen (Fng), C-reactive protein (CRP) or to the complement components factor $\mathrm{H}(\mathrm{FH})$, factor I (FI), factor $\mathrm{B}$ (FB), C1q and C3 was quantified by ELISA using anti-GST antibodies. Columns and bars indicate means \pm SD from three independent experiments conducted in duplicate.

B. Dose-dependency of PbsP-Plg interactions. ELISA assays were performed with immobilized Plg, to which rPbsP was added at the indicated concentrations. Binding was detected using anti-GST antibodies. Points and bars indicate means \pm SD from three independent experiments conducted in duplicate.

C. Far Western blot analysis of PbsP/Plg interactions. Far western blot analyses were done with $\mathrm{rPbsP}$ and GST (as negative control) on membranes probed and revealed with Plg and anti-Plg (left panel), and, reciprocally, with Plg on membranes probed and revealed with $\mathrm{rPbs} \mathrm{P}$ and anti-rPbsP (right panel). Numbers indicate the molecular mass of protein standards in $\mathrm{kDa}$.

D. Binding affinity of PbsP to Plg. Binding is measured as response units (RU) against time by surface plasmon resonance with immobilized rPbsP on a CM5 chip coated with anti-GST and increasing concentrations of Plg ranging from 0.40 (lowermost trace) to $4 \mu \mathrm{M}$ (uppermost trace). The sensor-graph is representative of three independent experiments conducted in duplicate and the affinity was calculated from curve fitting to a plot of the RU values against Plg concentration (right graph).

E. Selective inhibition of PbsP-Plg interactions. Competitive ELISA assays were done with immobilized Plg to which $\mathrm{rPbsP}$ was added in the presence of the indicated concentrations of 6-aminocaproic acid (6-ACA), L-Lysine, or L-Alanine, used as a negative control. Points and bars indicate means \pm SD from three independent experiments conducted in duplicate. 
F. Binding of PbsP domains to Plg. Schematic representation of recombinant $\mathrm{PbsP}$ domains produced as gluthatione-S-transferase (GST) fusion proteins and the corresponding.ELISA assays performed with immobilized Plg, to which the entire protein or its fragments were added at the indicated concentrations. Binding was detected using anti-GST antibodies. Points and bars indicate means \pm SD from three independent experiments conducted in duplicate.

\section{Figure 4. PbsP-bound Plg is converted into plasmin by host activators.}

A. Activation by tPA of PbsP-bound Plg. Immobilized $\mathrm{rPbsP}$ or GST were incubated in microplates with Plg with or without the Plg activator tPA. Activation of rPbsP-bound Plg was quantified with the chromogenic Pln substrate S-2251 (0.6 mM). Points and bars indicate means \pm standard deviations from 3 independent experiments performed in triplicate.

B. Degradation of fibrinogen by activated $\mathrm{Plg}-\mathrm{PbsP}$ complexes. Immobilized $\mathrm{rPbsP}$ was incubated with Plg, washed, and incubated with tPA and Fng. At the indicated time points, degradation of the three Fng chains was followed using polyacrylamide gel electrophoresis. A representative Coomassie-stained gel from three experiments is shown.

\section{Figure 5. Plg binding and activation on the GBS surface are dependent on PbsP.}

The following GBS strains were compared: WT, NEM316 wild-type strain; $\Delta p b s P$, isogenic $p b s P$ deletion mutant; $\Delta p b s P+p b s P, \Delta p b s P$ strain carrying a complementing vector with constitutive $p b s P$ expression; $\mathrm{WT}+\mathrm{P}_{\text {tet }}$, and $\Delta p b s P+\mathrm{P}_{\text {tet, }}$, control strains carrying a vector without inserts; *, p $<0.05$ by one-Way ANOVA and Tukey's multiple comparisons test.

Columns and bars indicate the means $\pm \mathrm{SD}$ of three independent experiments conducted in duplicate. 
A. GBS binding to Plg. Bacteria were incubated with Plg followed by fluorescent anti-Plg antibodies and analyzed by FACs. Shown is the increase in mean fluorescent intensity (MFI) measured on 10,000 events per population.

B. Plg activation on the GBS surface. After Plg binding to GBS (as in A), the Plg activator tPA was added and Pln activity was measured optically with the chromogenic Pln substrate D-Val-Leu-Lys-p-nitroanilide.

\section{Figure 6. In vitro translocation of GBS through human brain endothelial cells is} dependent on Plg-PbsP interactions.

Adhesion (A), invasion (B) and transmigration (C) were assessed using the brain endothelial cell line hCMEC/D3. GBS strains are as in Figs. 2 and $5 ; *=p<0.05$ by one-Way ANOVA and Tukey's multiple comparisons test. Columns and bars represent means $+\mathrm{SD}$ of CFU values from three independent experiments conducted in duplicate.

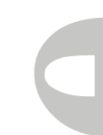

\section{Figure 7. PbsP is required for GBS virulence.}

A. Effects of PbsP on survival of GBS-infected mice. Adult CD1 mice ( $\mathrm{n}=16$ per group) were infected i.v. with $5 \times 10^{8}$ CFUs of WT NEM 316 or the $\triangle p b s P$ mutant and survival was monitored. *, $\mathrm{p}<0.05$ by log-rank Kaplan-Meyer analysis.

B-D. Effects of PbsP on organ colonization. Bacterial burden in blood (B), kidneys (C), and brains (D) were quantified 48 hours after i.v. challenge with $5 \times 10^{8}$ CFUs of WT or $\triangle p b s P$ strains. $*=p<0.05$ by the Mann-Whitney $U$ test.

\section{Figure 8. PbsP-based immunization protects against lethal GBS infection in mice.}

Animals ( $\mathrm{n}=10$ per group) were immunized with $\mathrm{rPbsP}$ protein or with GST as a control and 
challenged i.v. with $2 \times 10^{8} \mathrm{CFU} /$ mouse of wild type strain NEM316. * $*$ p $<0.05$ by $\log$ rank Kaplan-Meyer analysis.

Figure S1. Effect of deletion of the pbsP gene on Gram stain morphology and growth curves of GBS

Gram stain (A, 100X magnification) and growth curves in Todd Hewitt broth (B). The following GBS strains were compared: WT, NEM316 wild-type strain; $\Delta p b s P$, isogenic $p b s P$ deletion mutant; $\triangle p b s P+p b s P, \Delta p b s P$ strain carrying a complementing vector with constitutive $p b s P$ expression.

\section{Figure S2. Phylogenetic analysis of streptococcal SSURE domains.}

The two SSURE domains (SSURE-1 and -2) of the GBS protein PbsP from strain NEM316, the four and six SSURE domains (SSURE-1 to -6) of the pneumococcal protein PfbB (PavB) from, respectively, strains TIGR4 and R6 were aligned and a phylogenetic tree was computed using the Neighbor Joining method. This analysis defines three clusters supported by significant bootstrap values $(100 \%)$ calculated from 1,000 replicates. The scale bar (neighbour-joining distance) represents the percentage sequence divergence. 


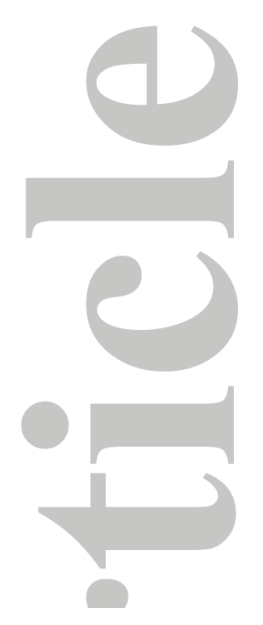

Fig. 1

A

$\mathrm{NH}_{2}=\mathrm{SP}$ SS-terminal $\quad$ SSURE2

B

SSURE1 EVKKSTDTAFKQTVDVPAHYVNAAKGNGPFLAGVNQTIPYEAFGGDGMLTRLILKSSEGA

SSURE2 EVKNSLKMAFKEKVDVPAKYVSAAKAKGPFLAGVNETIPYEAFGGDGMLTRLILKASEGA $\star * *:{ }^{*} . * * *: . * * * * *: * * . * * * .: * * * * * * * *: * * * * * * * * * * * * * * * * * * *: * * * *$

SSURE1 KWSDNGVDKNSPLLPLKGLTKGKYFYQVSLNGNTTGKEGQALLDQIKANDKHSYQATIRV

SSURE2 KWSDNGVDKNSPLLPLKDLTKGKYFYQVSLNGNTAGKKGQALLDQIKANGSHTYQATITI

SSURE1 YGAKDGKVDLKNMISQKMVTINIPHITTDM

SSURE2 YGTKDGKVDMNTILGQKTVMIHINVAKKDM

${ }^{* *}: * * * * *:::::{ }^{* *}{ }^{*}{ }^{*}{ }^{*} \quad \ldots{ }^{* *}$

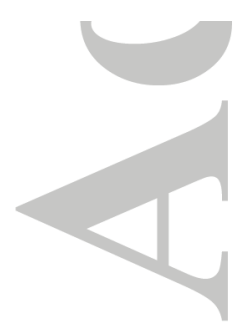




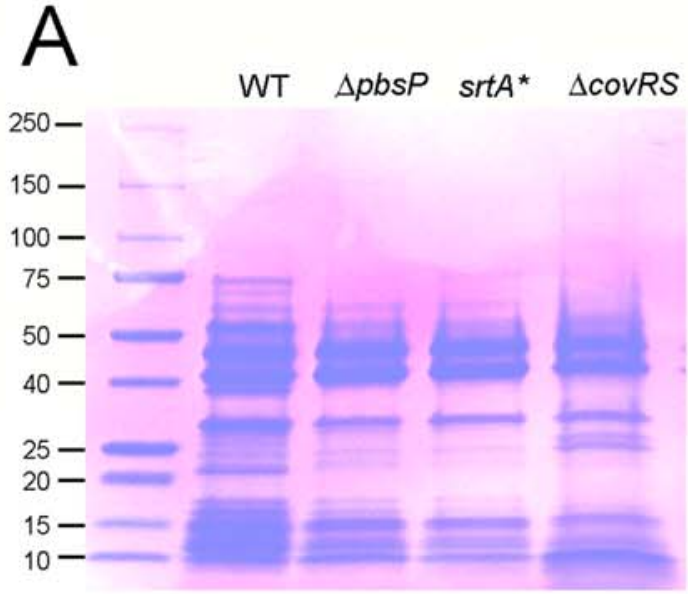

Cell-wall extracts

Coomassie

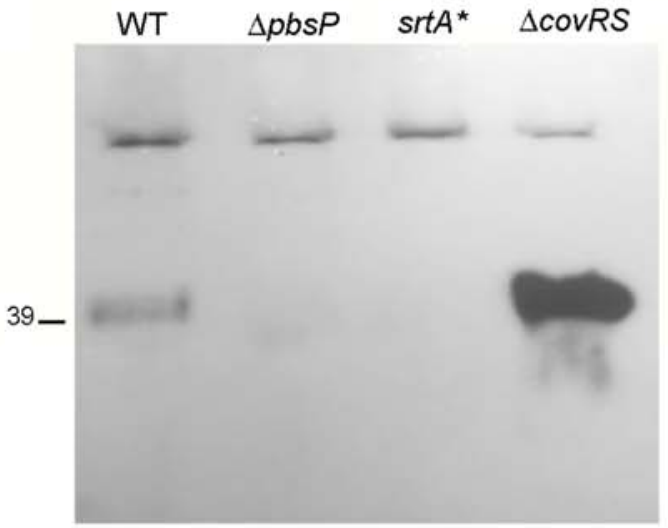

Cell-wall extracts

Western blot

B

Test: $\alpha$-GST-PbsP $+\alpha$-mouse IgG

Control: $\alpha$-GST $+\alpha$-mouse IgG
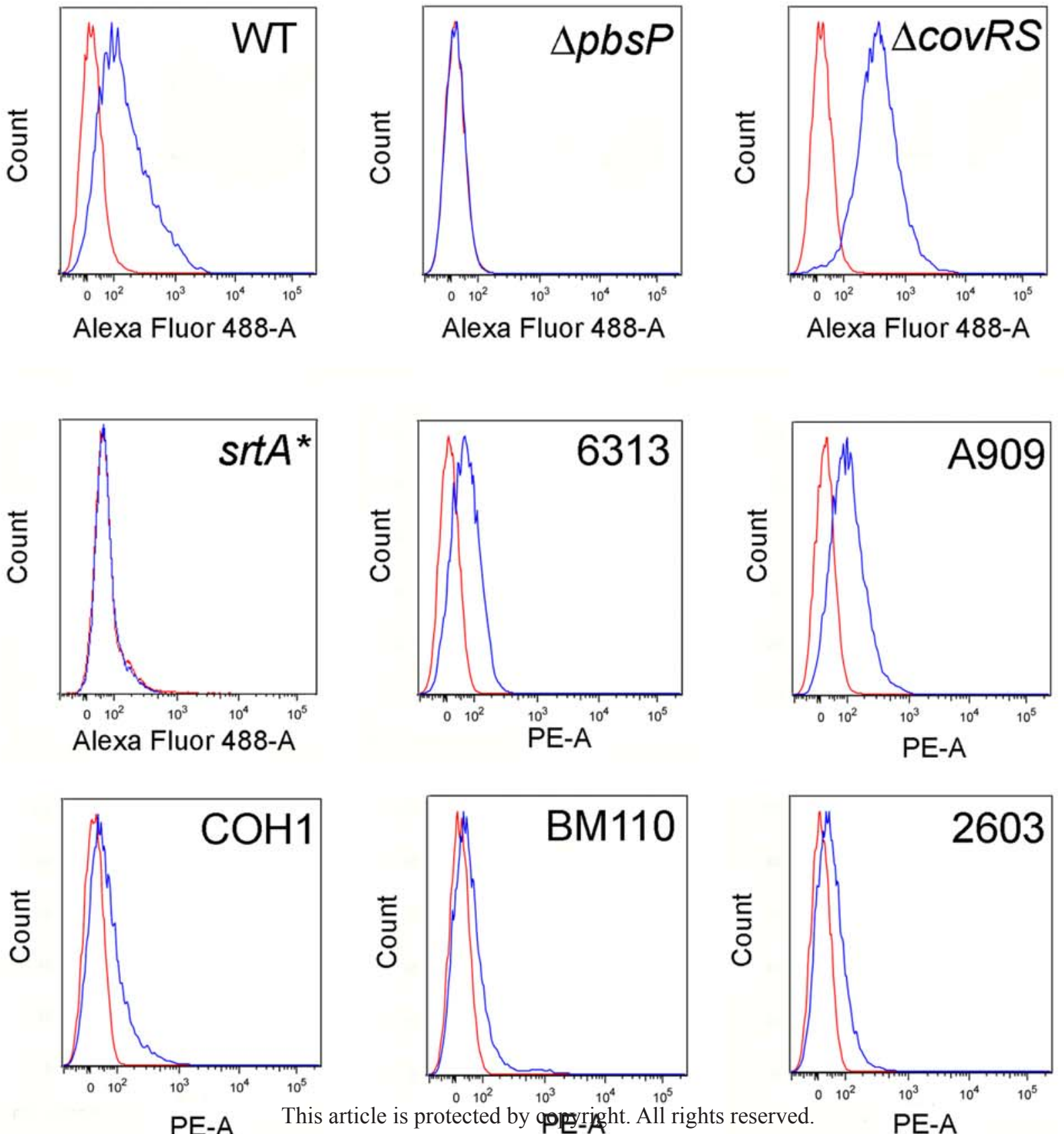
Fig. 3
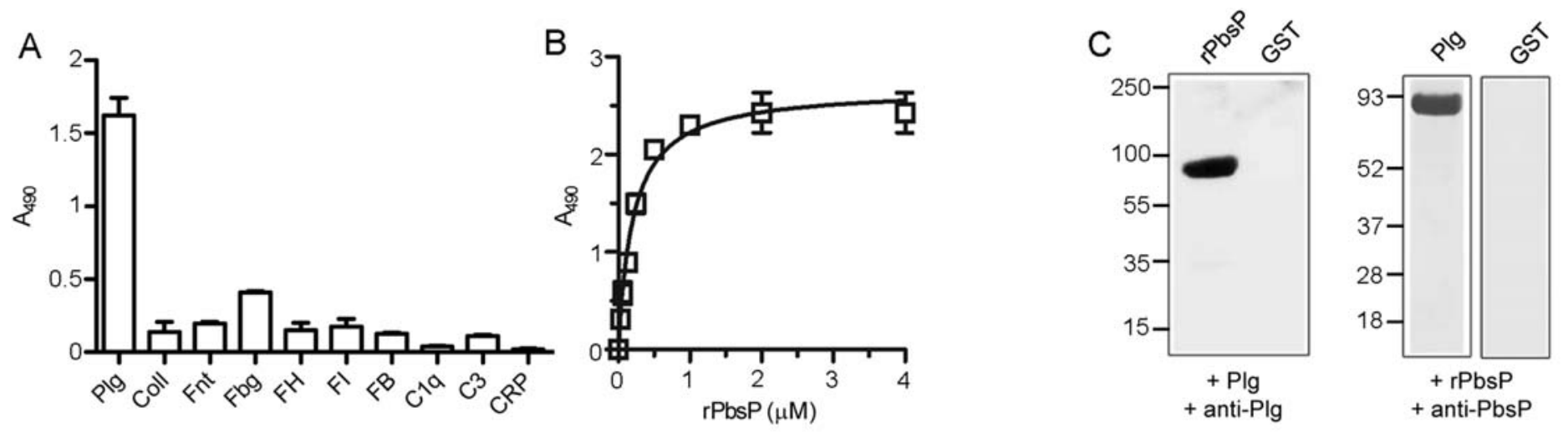

D

E
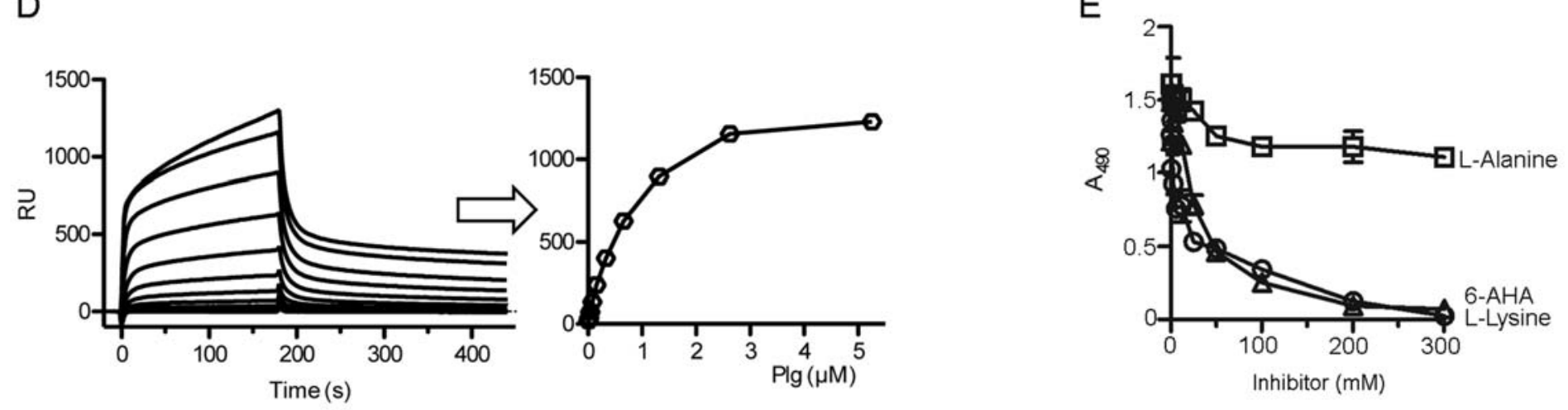

F
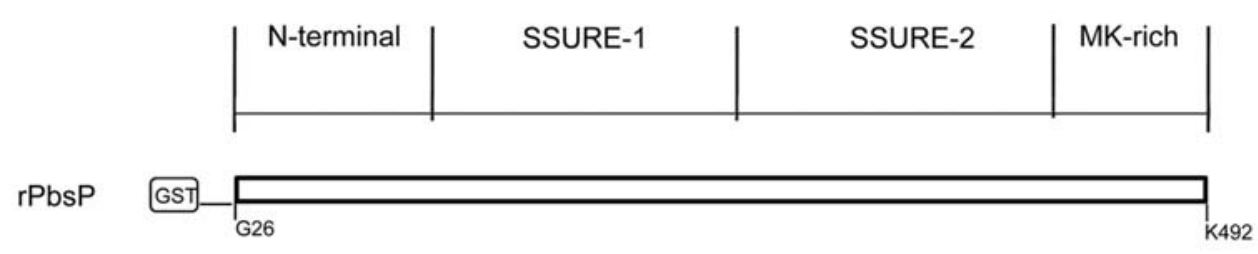

rSSURE-1+2

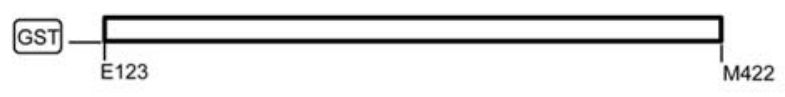

rSSURE-2

rMK-rich
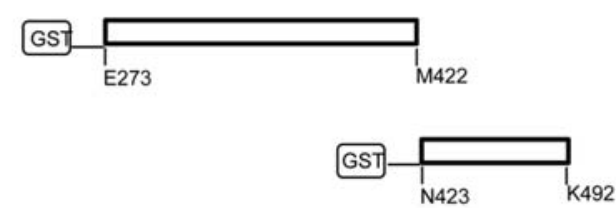

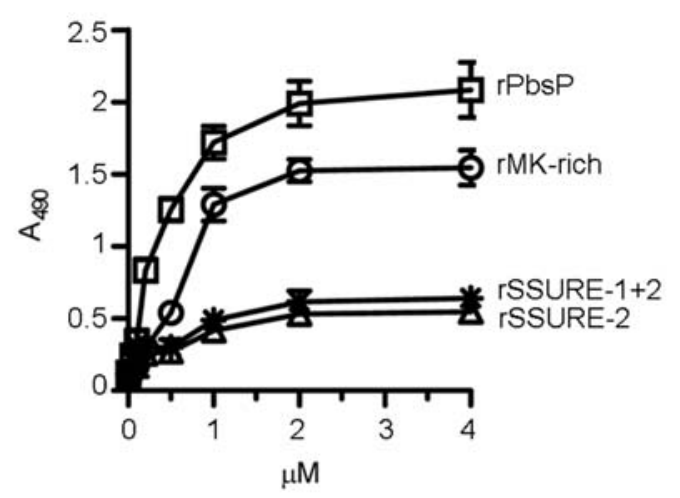


A
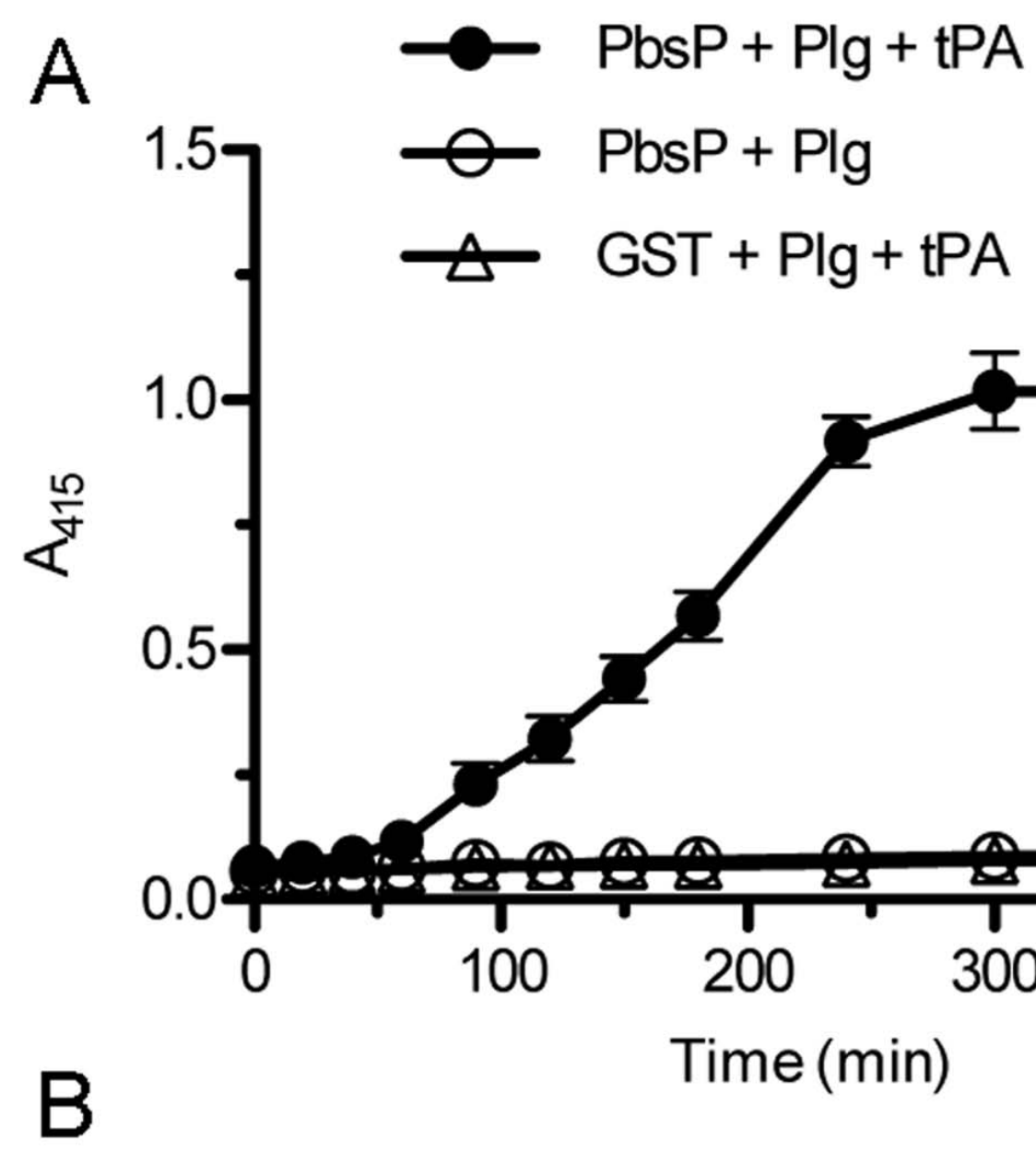

$$
\begin{array}{ll}
1.5 & -\mathrm{PbsP}+\mathrm{Plg} \\
- & \mathrm{GST}+\mathrm{Plg}+\mathrm{tPA}
\end{array}
$$

$1.0-$

$\frac{1}{n}$

$\mathrm{B}$

Time (min)

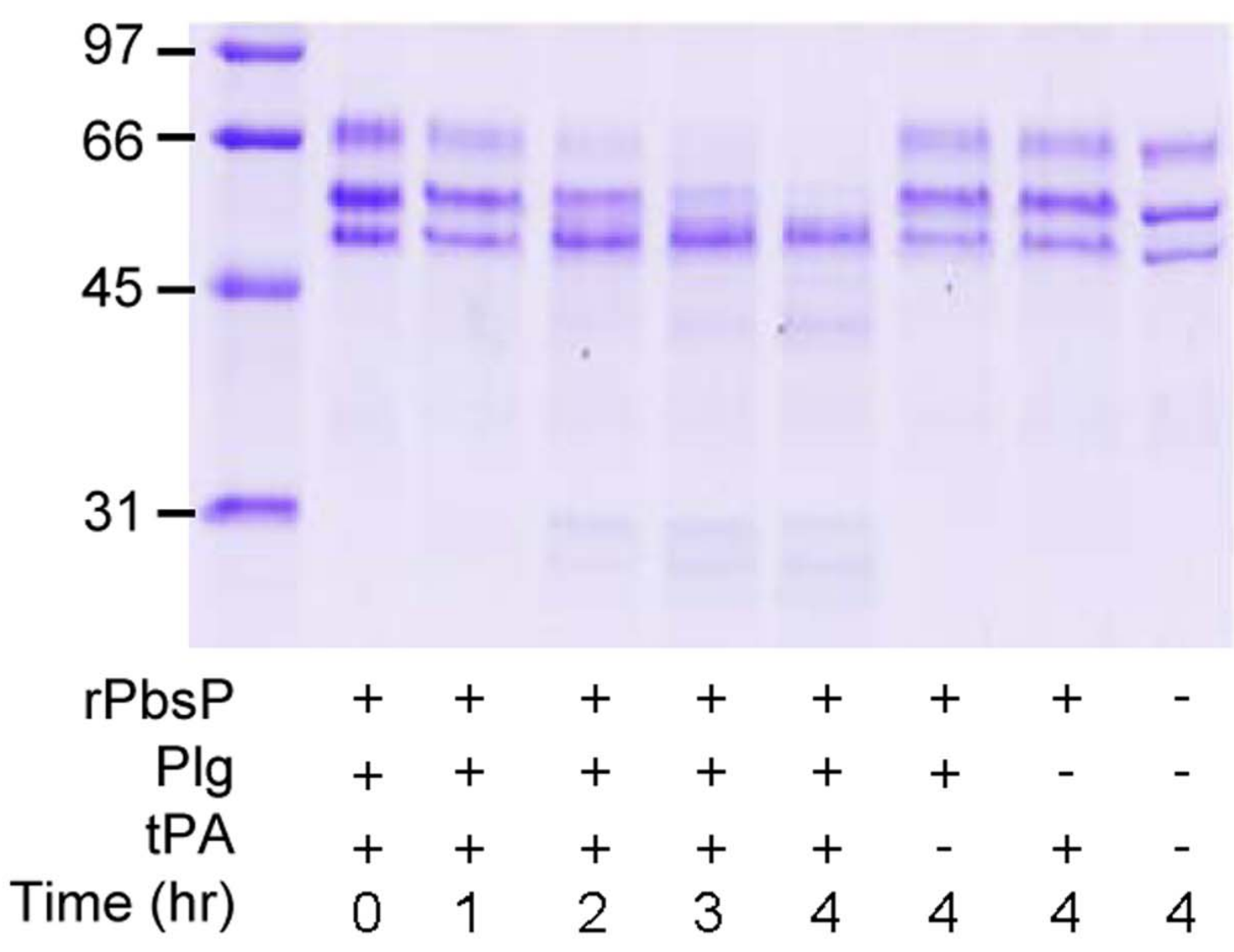


Fig.5

A

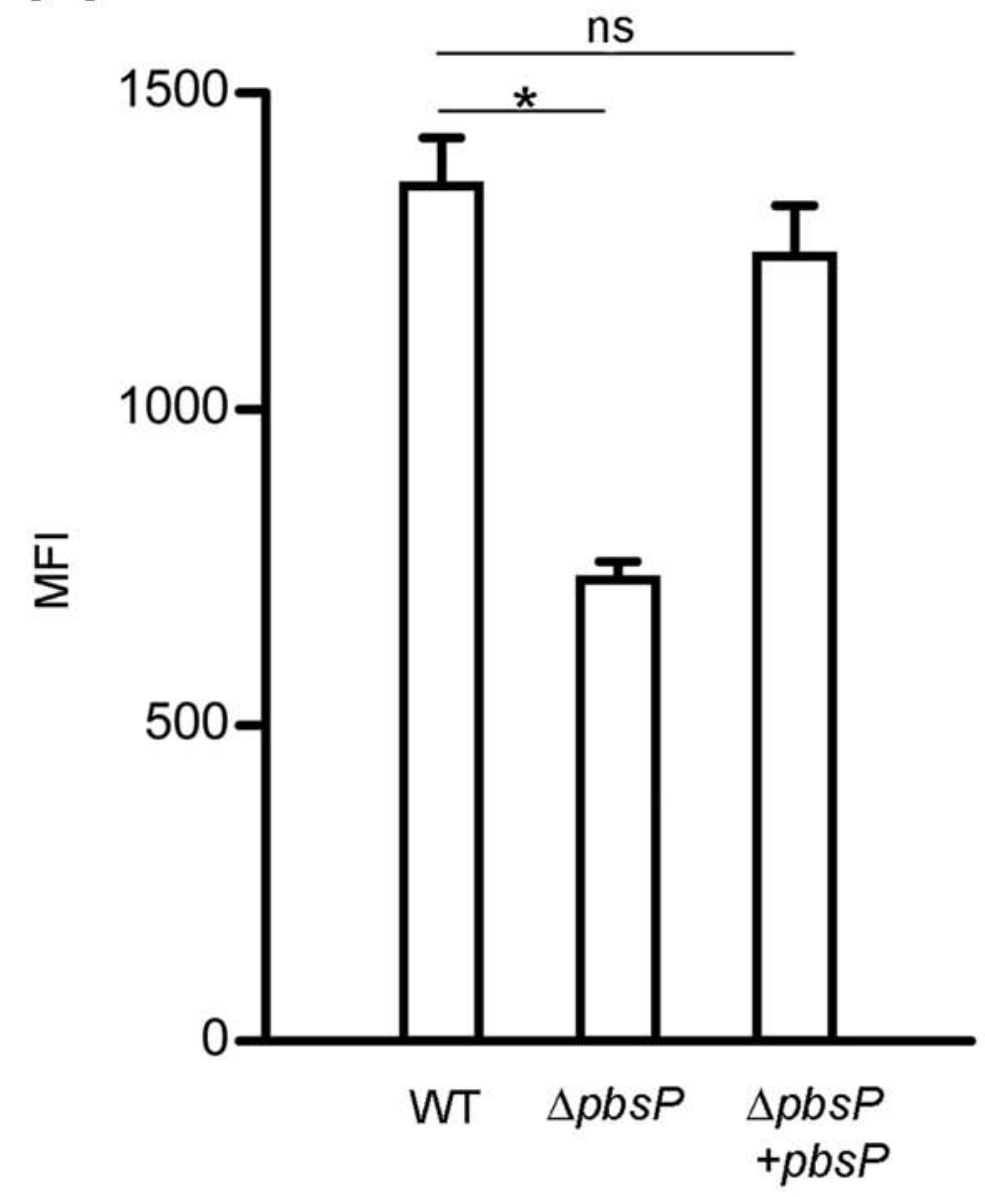

B

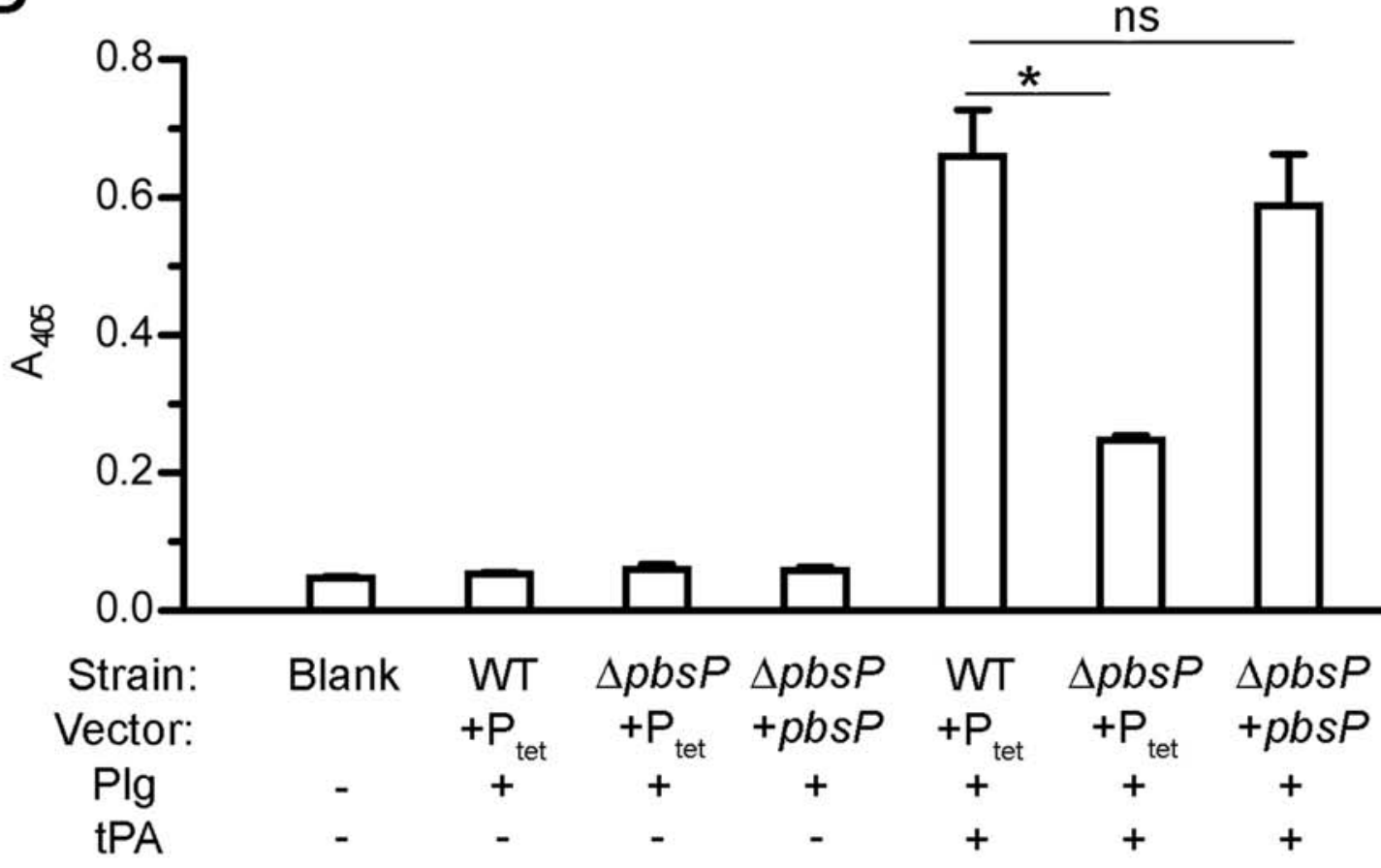


A

Fig. 6
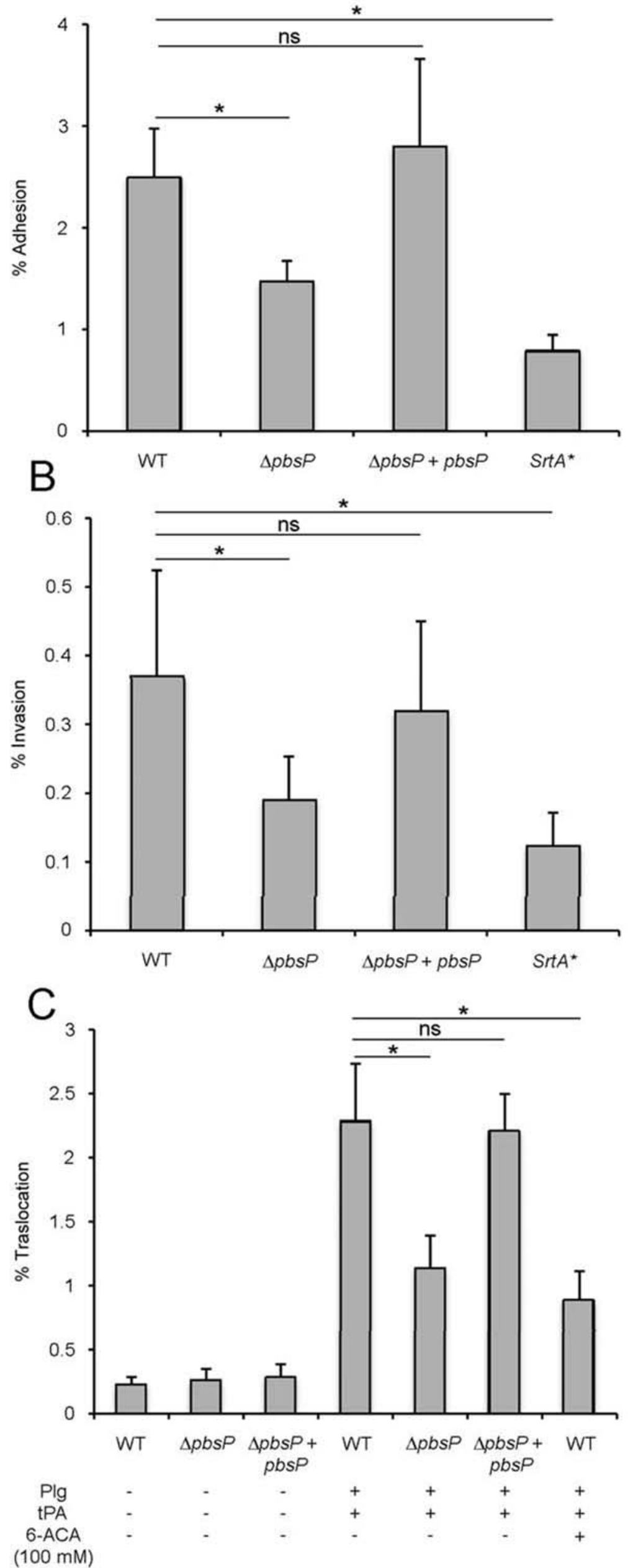

This article is protected by copyright. All rights reserved. 


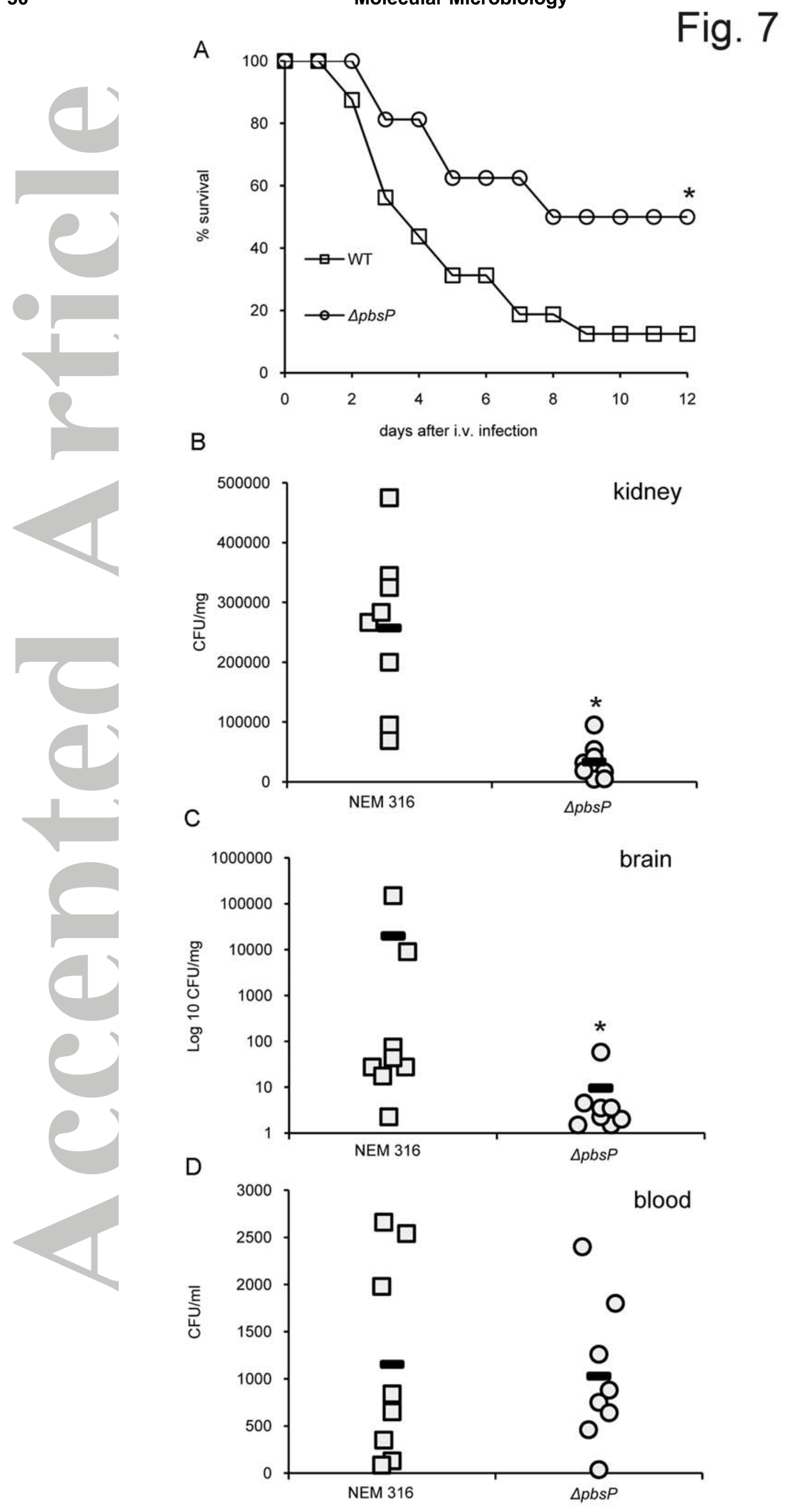


Fig. 8

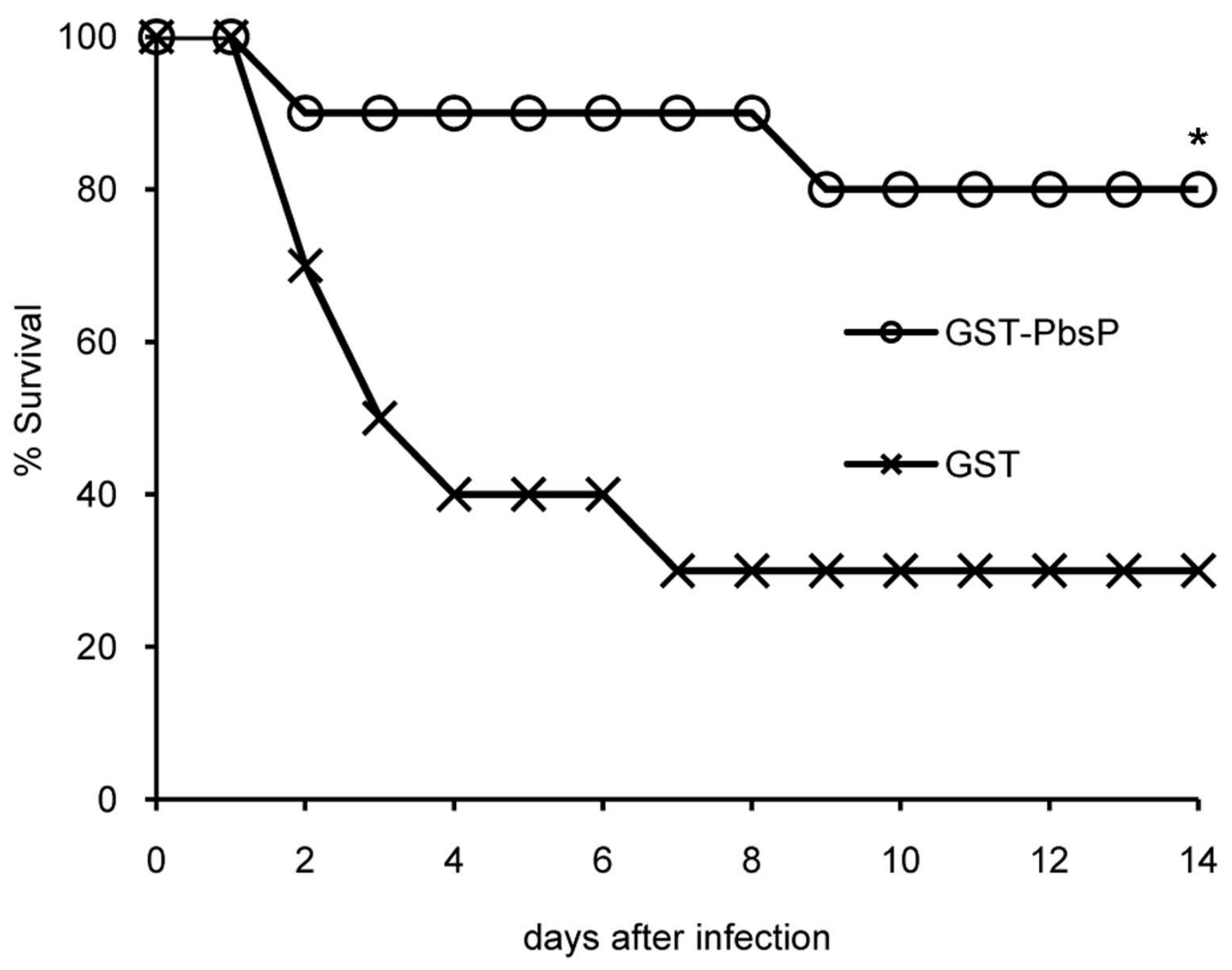



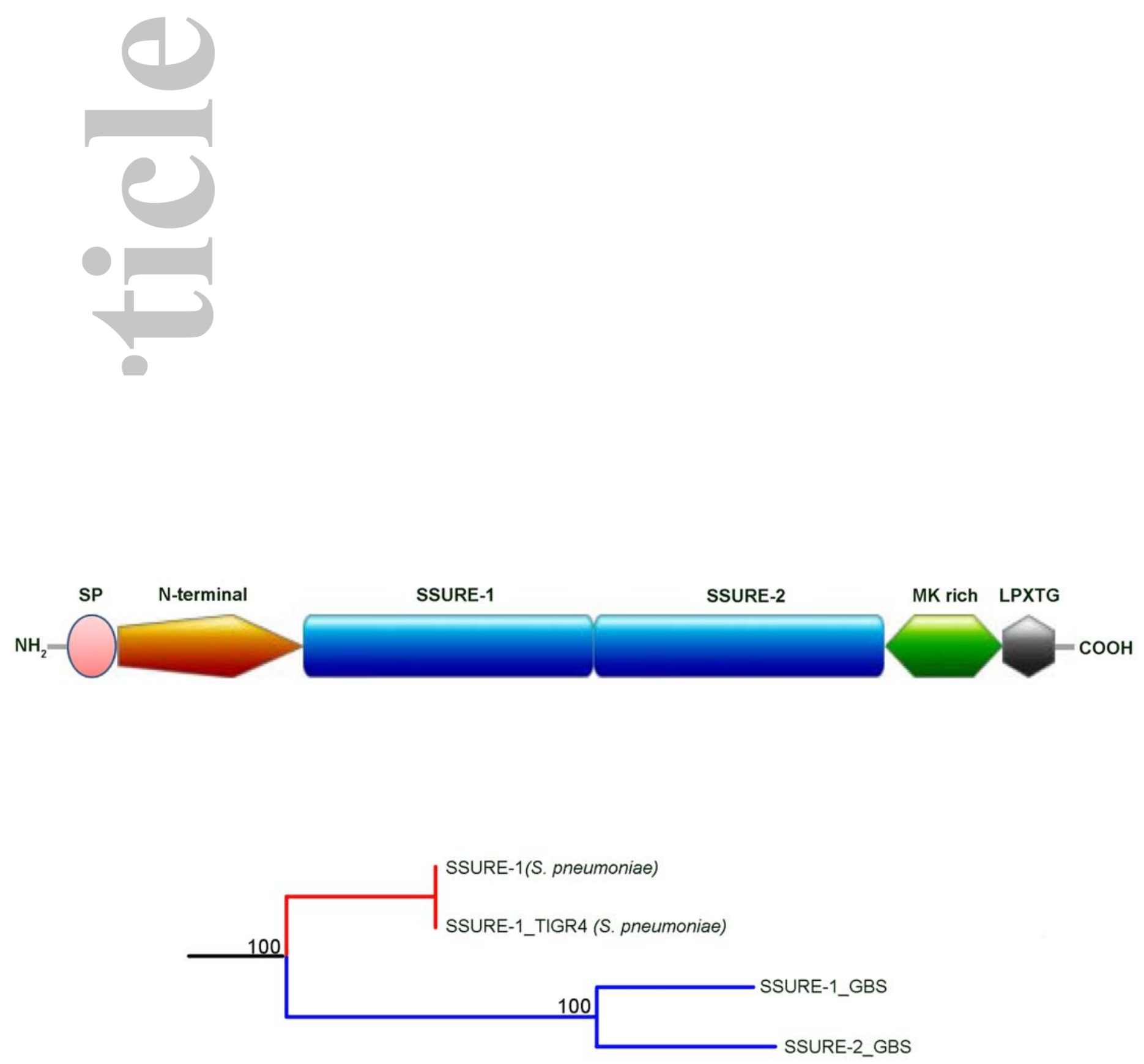
We describe here Plasminogen binding surface Protein, or PbsP, a highly conserved virulence factor of group B streptococci. This adhesin contains two Streptococcal Surface Repeat domains, a methionine- and lysine-rich region and an LPXTG cell-wall anchoring motif. PbsP largely mediates the ability of group B streptococcal strain NEM316 to bind plasminogen, acquire proteolytic activity and transmigrate through brain endothelial cells, resulting in meningoencephalitis. Moreover, immunization of mice with PbsP confers protective immunity.
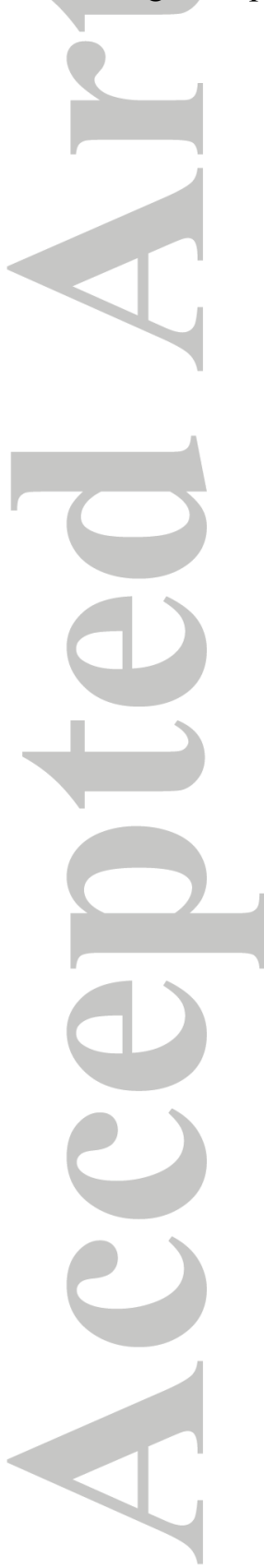